\title{
AN OVERVIEW OF THE MAGNETIC FUSION ENERGY DEVELOPMENT AND TECHNOLOGY PROGRAM
}

March 1978 


\section{DISCLAIMER}

This report was prepared as an account of work sponsored by an agency of the United States Government. Neither the United States Government nor any agency Thereof, nor any of their employees, makes any warranty, express or implied, or assumes any legal liability or responsibility for the accuracy, completeness, or usefulness of any information, apparatus, product, or process disclosed, or represents that its use would not infringe privately owned rights. Reference herein to any specific commercial product, process, or service by trade name, trademark, manufacturer, or otherwise does not necessarily constitute or imply its endorsement, recommendation, or favoring by the United States Government or any agency thereof. The views and opinions of authors expressed herein do not necessarily state or reflect those of the United States Government or any agency thereof. 


\section{DISCLAIMER}

Portions of this document may be illegible in electronic image products. Images are produced from the best available original document. 


\section{NOTICE}

This report was prepared by the Grumman Aerospace Corporation as an account of work sponsored by the United States Government. Neither the United States nor the United States Department of Energy, nor any of their employees, nor any of their contractors, subcontractors, or their employees, makes any warranty, express or implied, or assumes any legal liability or responsibility for the accuracy, completeness, or usefulness of any information, apparatus, product or process disclosed, or represents that its use would not infringe privately owned rights.

Available from:

National Technical Information Service (NTIS)

U.S. Department of Commerce

5285 Port Royal Road

Springfield, Virginia 22161

Price: Printed Copy: $\$ 4.50$

Microfiche: $\quad \$ 3.00$ 
U.S. Department of Energy Assistant Secretary for Energy Technology Office of Magnetic Fusion Energy Washington, DC 20545 
Why

Magnetic

Fusion?

America is an energetic nation. At work, at play, travelling, or simply relaxing, we consume energy at a staggering rate as we enjoy the fruits of a trillion dullas economy. But we're more aware today than ever that to keep the engines of our economy fueled and running is not as easy as it once was.

Over the past few decades, there have been growing indications that despite optimistic estimates of untapped resources, we would bc faced one day with the hard and unpleasant fact that our riches were finite and we would become increasingly dependent on energy imports. The United States became more aware of this fact in the early 1970's when energy markets worldwide were thrown into chaos during the oil embargo. Energy planners now realize that we no longer can afford abrupt termination of energy supplies, or coercion and

\section{CONTENTS}

\section{INTRODUCTION}

\section{Why Magnetic Fusion?}

The Challenges

Progress

The Fufure

How Do We Get There?

FUSION SYSTEM ENGINEERING

AMD ADVANCED DESIGK

PLASWA ENGIHEERING

MAGNETIC SYSTEWS

MATERIALS

ENVIRONMENT AND SAFETY

ALTERNATE ENERGY APPLICATIONS

GLOSSARY ii

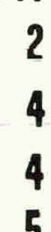

intimidation by other energy-rich nations. To pay any price for a commodity growing scarcer each day simply won't do.

The nation is looking more seriously at using what we have to better advantage, although we are aware that reverting to coal, finding or buying more petroleum and natural gas, or widening the use of fissionable fuels are not long-range solutions. Moreover, it is clear that the only realistic answer to the energy problem ultimately lies in the development of new sources, extracted from a high-yield raw material so plentitul as to preclude control of its supply by any nation or bloc.

One such material is sea water. Sea water contains deuterium, an abundant isotype of hydrogen. Deuterium, or "heavy hydrogen", cxists in sea water in small quantities, but the oceans contain enough to supply our needs for a billion years. The deuterium in a gallon of sea water has an energy value equal to 300 gallons of gasoline, and its extraction cost is measured in pennies per gallon.

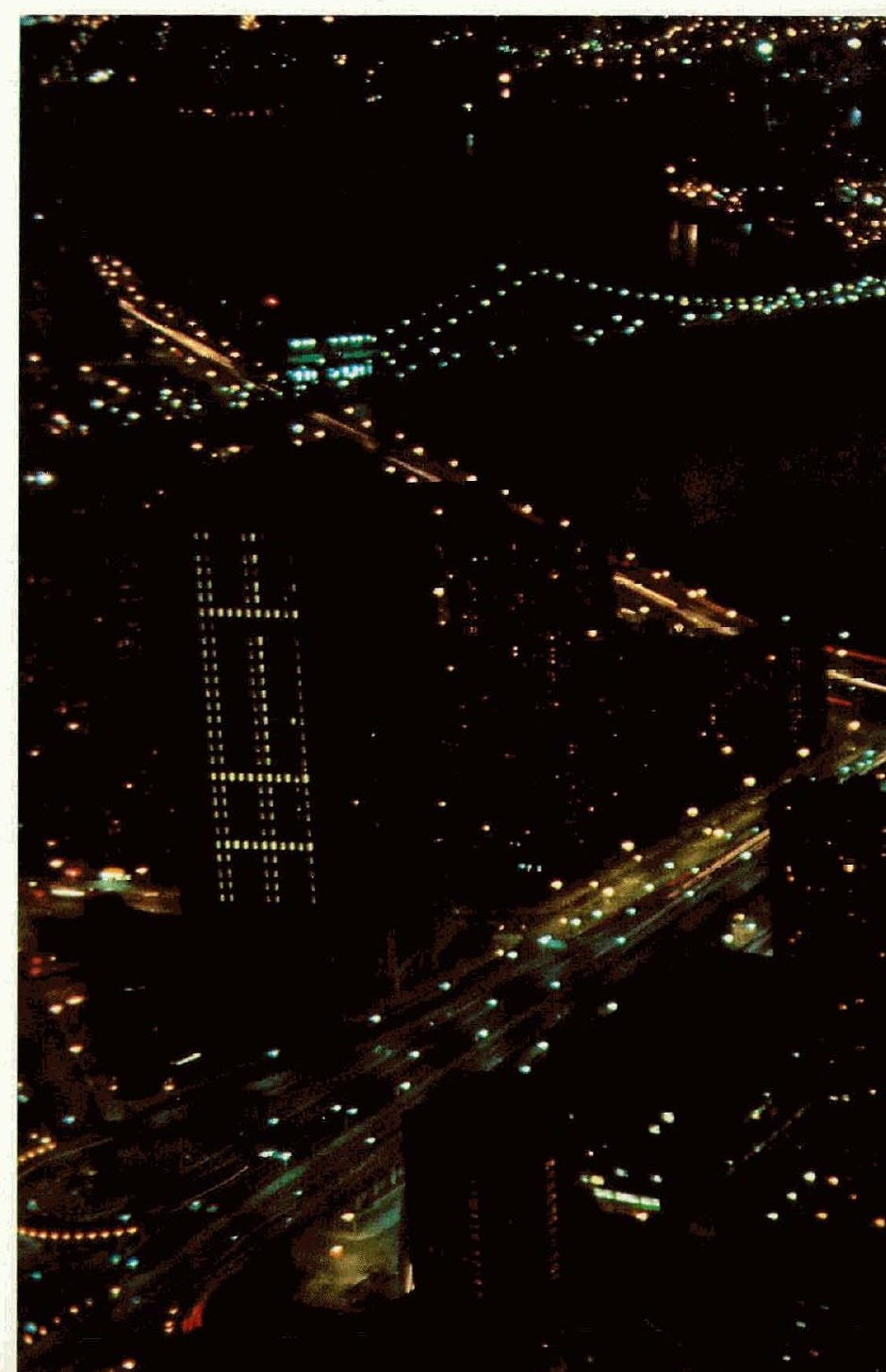


Converting the energy from deuterium into a usable form is accomplished by the process of nuclear fusion. Fusion releases no chemical pollutants to the atmosphere since there are no combustion products. There are also no "ashes", except helium, a harmless and useful gas. There is no inventory of weapons-related uranium or plutonium materials associated with fusion; hence, there is no risk of diversion.

Nuclear fusion, particularly magnetic nuclear fusion, is a most attractive process because it offers high energy return, a prerequisite for central power generating stations of electric utilities. Reactors can safely be located close to population centers, thereby incurring lower transmission losses. Furthermore, inclement weather cannot interrupt operation, and the process does not demand large tracts of real estate.

As in any nuclear reaction process, there are risks. For instance, one of the materials being considered for fuel is radioactive tritium; however, its use is intended only for first-generation reactors. With the introduction of second- generation reactors, its use is expected to decline sharply. The radiation originating from neutron activation of reactor materials is not expected to pose a significant waste disposal problem since the radiation is locked up in the solid structural material and has a low hazard index.

In addition, there are very difficult physics and engineering questions that must be successfully resolved before fusion power reactors can be made a safe, economically competitive energy resource. This booklet summarizes the progress made thus far in nuclear fusion development and technology.

To make fusion power a reality in the 21 st century, development must proceed through a national commitment to long-range energy program priorities. Much has been done, but much remains to be done, and time is short.

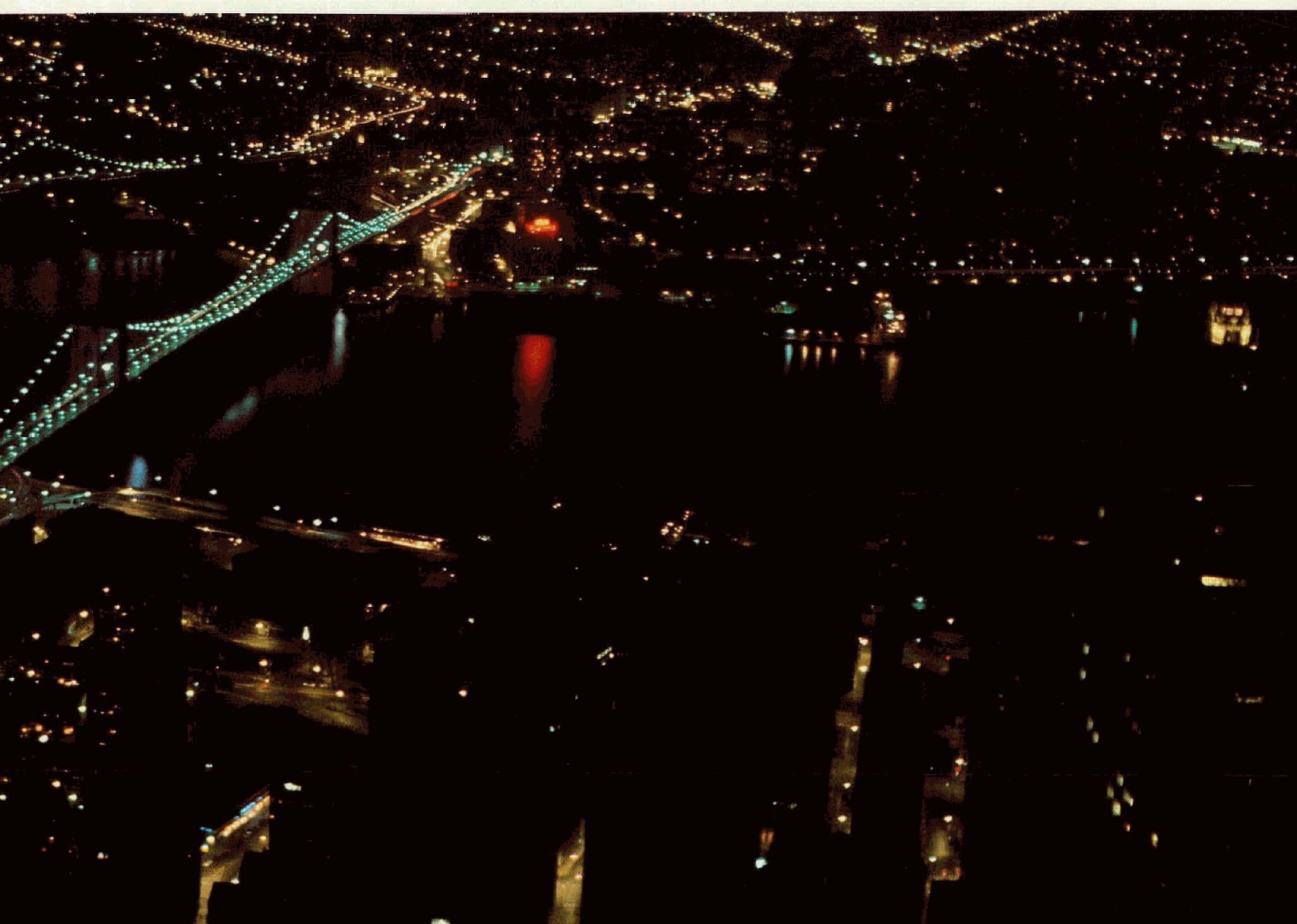


Developing economical and safe fusion power ranks among the most challenging technical problems ever attacked by mankind. Some of the obstacles that lie in the path include:

- Designing and building powerful superconducting cryogenically cooled electromagnets to keep the intensely hot plasma from contacting the vessel walls, and to shape and stabilize the plasma to desired requirements.

- Selecting or developing materials that must meet unusually stringent requirements, such as maintaining strength at cryogenic temperatures and withstanding intense neutron bombardment.
- Coping with plasma temperatures of 100 million ${ }^{\circ} \mathrm{C}$, about seven times hotter than the sun's interior.

- Creating vacuums of $10^{-8}$ torr, rivalling the low pressures encountered miles into outer space.

- Heating isotopes of hydrogen gas (deuterium or tritium) to plasma temperatures.

- Ensuring safety to the operators and the public.

- Evaluating the several competing theoretical approaches and design concepts, and selecting the most promising nnes

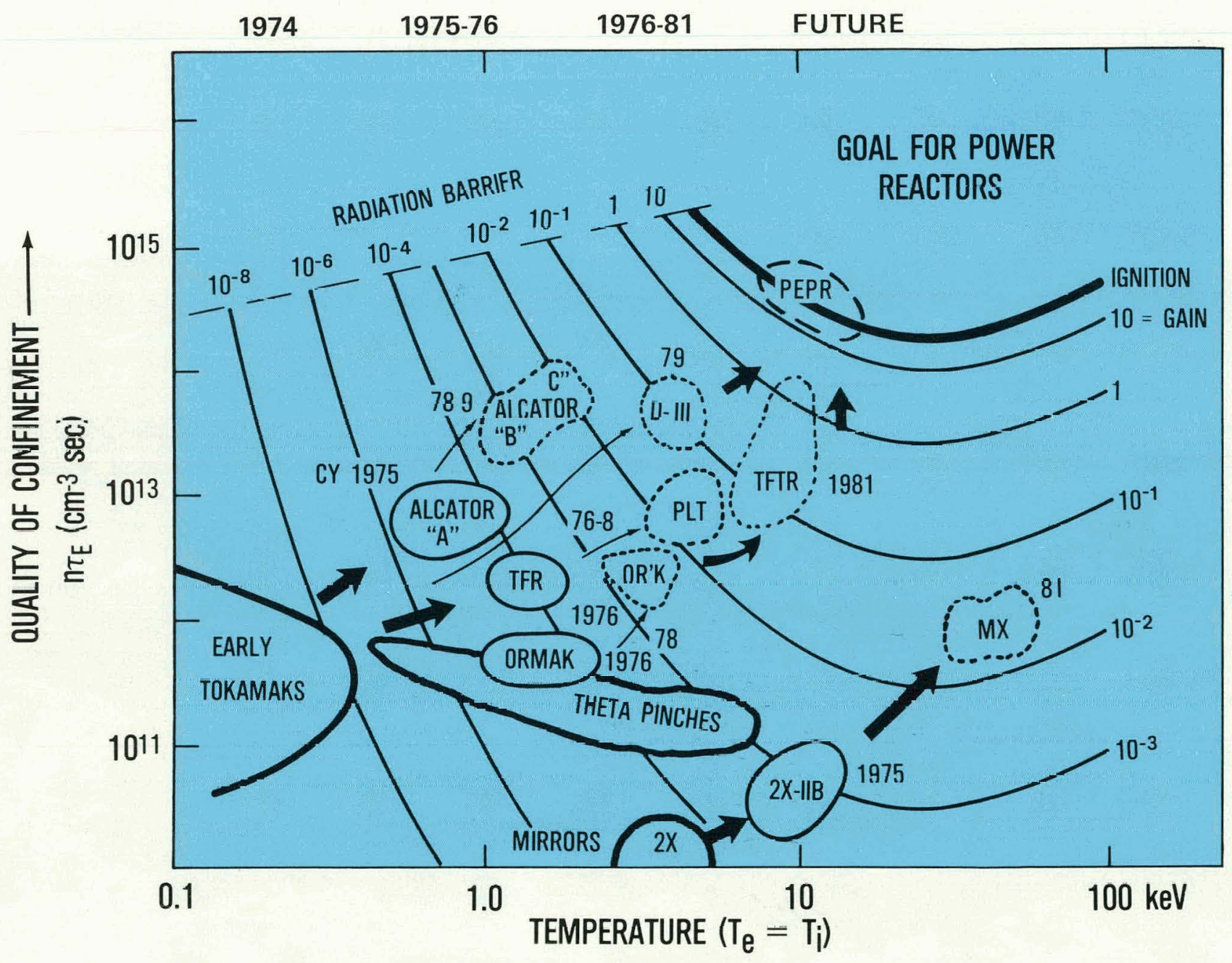

The minimum condition for ignition of a pure deuterium-tritium fusion plasma is plotted as a function of ion temperatures (in $\mathrm{keV}$ ), and as a function of the product of plasma density and energy confinement time $\left(n \tau_{E}\right)$. Achieved and projected results for peak $T_{i}$ and peak $n \tau_{E}$ for various experiments are plotted on the same grid. Contours of constant thermonuclear energy gain (fusion power density at $17.6 \mathrm{meV} /$ fusion divided by external power density to maintain plasma temperature against losses) help to gauge progress toward the goal of an ignited plasma. 
- Developing techniques and equipment for maintaining and repairing major components by remote control.

- Designing complex, interactive systems for high reliability and long life.

- Developing and testing hardware systems to prove concepts.

- Providing instruments, methods and controls for measuring, diagnosing and controlling the conditions and devices previously described.

Although the problems are many and challenging, there has been encouraging progress toward solving them. Moreover, there is also growing confidence among scientists and engineers that with the necessary support and priorities, solutions can be found by the end of the century. If this support materializes, the reality of commercial fusion energy, using inexpensive and inexhaustible fuel, is a distinct possibility early in the 21 st century.

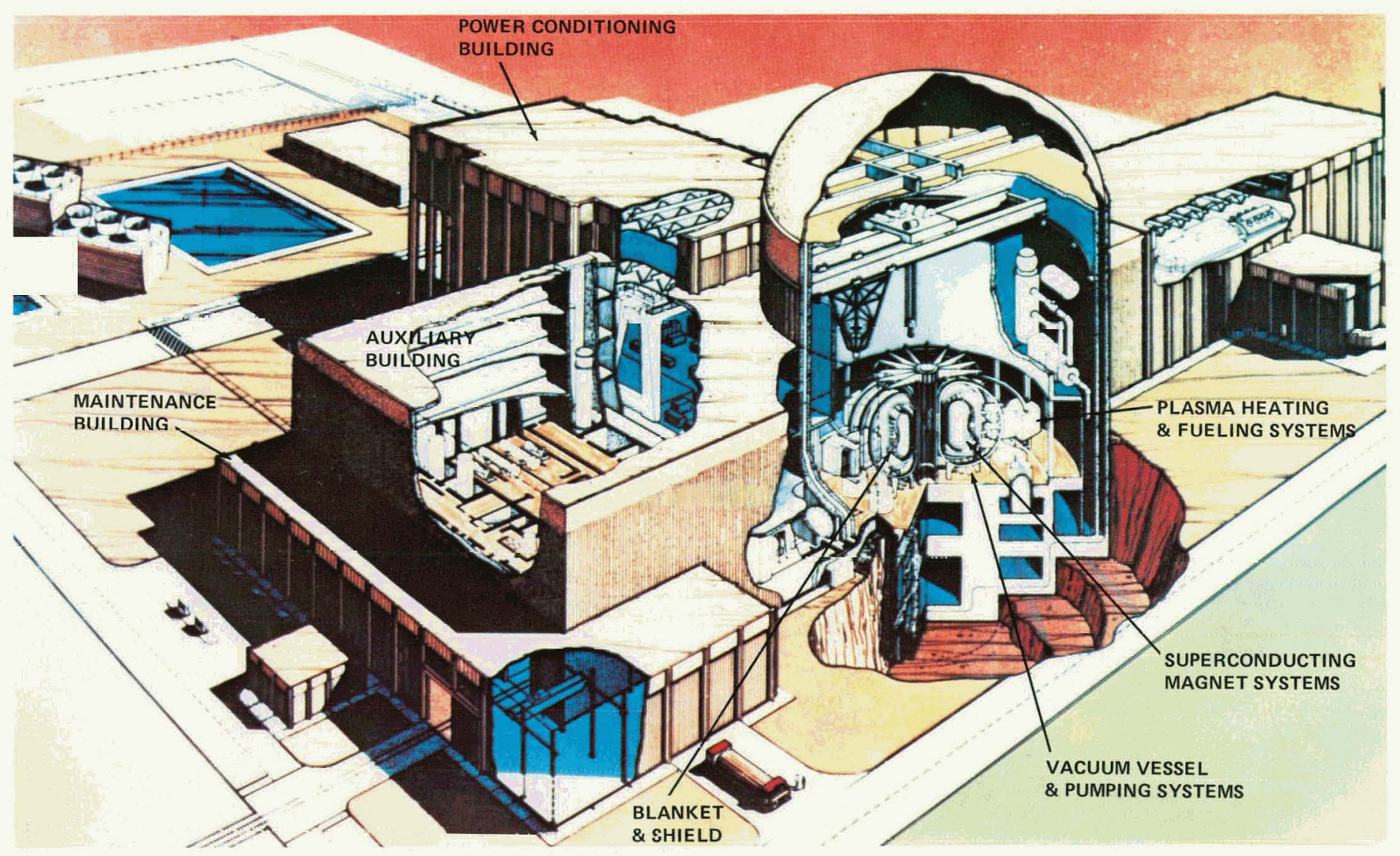

Fusion energy, typified in this artists's rendering of a Magnetic Fusion Electric Generating Plant, could meet mankind's needs utilizing a cheap and virtually inexhaustible supply of fuel. 


\section{Progress}

No one has yet built a fusion reactor that produces more power than it consumes (net power), but the gap to that goal is closing. Two of the leading candidates are: (1) "tokamaks" which magnetically confine plasmas in a doughnut-shaped vacuum chamber; and (2) "magnetic mirrors", which use magnetic fields to contain the plasma radially and at each end. The end magnets reflect, or "mirror", the plasma back into the confinement chamber.

The figure on page 2 summarizes the progress to date in reaching required values of the parameters deemed critical for successful operation.

\section{The Future}

The Office of Magnetic Fusion of the Department of Energy is developing plans to make commercial fusion power a practical reality before the turn of the century. These plans project an orderly and cost-effective blueprint for developing the building blocks needed to reach this goal. As a part of this program, the Department of Energy is soliciting the assistance of academia and private industry to involve the private sector early in the development program. The objectives are: to reduce R\&D costs; train and apply the best talent; and pave the way for increasing private investment once fusion energy nears commercial reality.

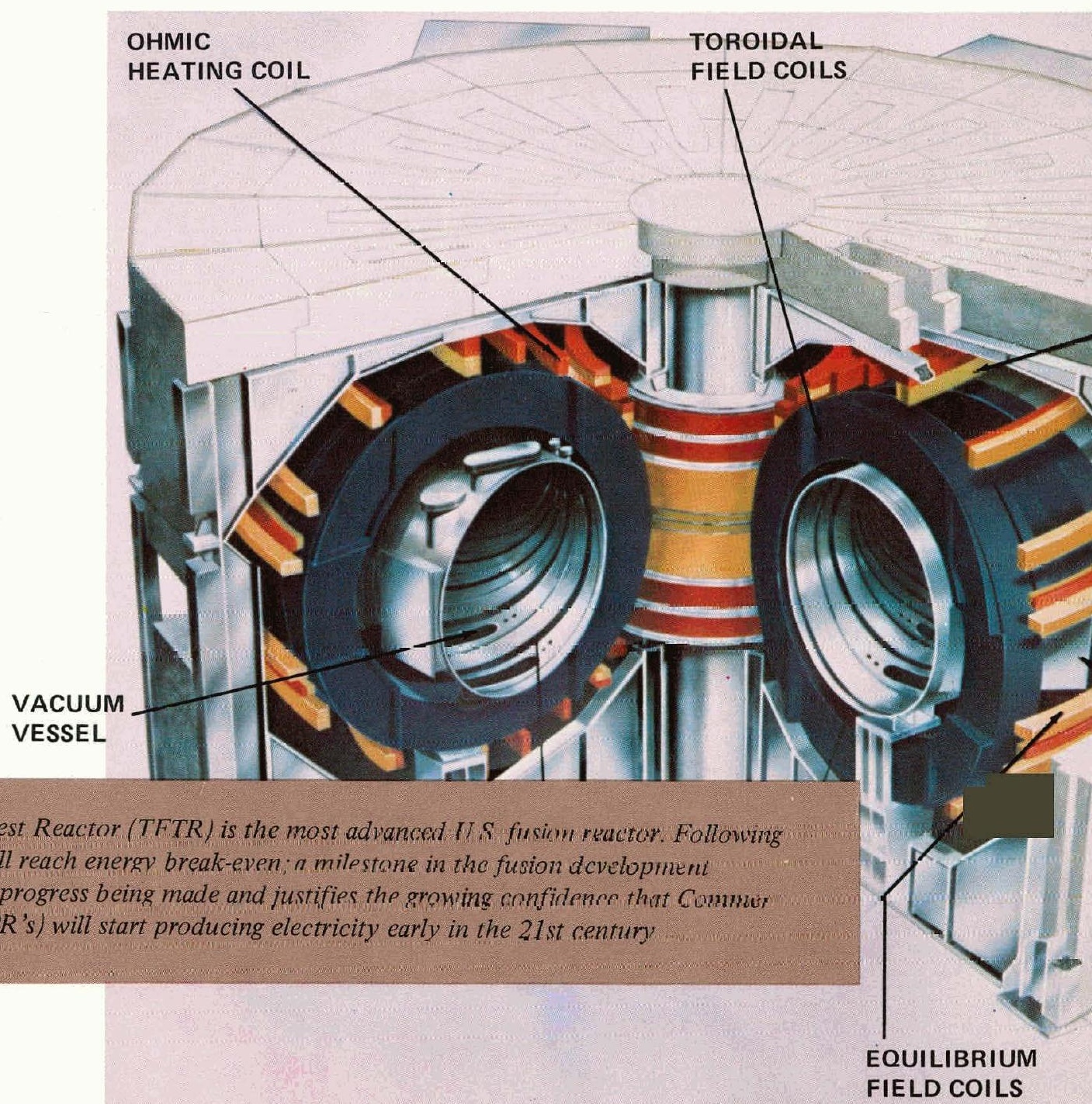

The Tokamak Fusion Test Reactor (TFTR) is the most advanced II S fusinn ruactor. Following operation in 1981, it will reach energv break-even; a milestone in the fusion dcvelopment program. It typifies the progress being made and justifies the growing confidener that Commer clal Power Keactors (CPR's) will start producing electricity early in the 21 st century 
Fusion system engineering conducts conceptual design studies of future fusion devices based on credible extrapolation of the physics known today. In addition, fusion system engineering initiates preliminary development of technology and key subsystems in such areas as tritium handling and containment, blankets and shields, and instrumentation and control, among others.

The conceptual design studies, which include tokamak, mirror and other promising confinement configurations, identify problems which supply feedback for new direction in the fusion research and development programs. In effect, these studies are the vanguards of the main efforts. For example, in the mid-1970's tokamak EPR design studies based on the physics of the day produced a number of large size EPRs that would have led to extraordinary capital costs. As a result of these studies, new impetus was given to the search for concepts to increase the power density and improve the physics.

\section{Tokamaks}

Tokamak reactor studies, based on more favorable experimental scaling results (i.e., operation at higher plasma densities and smaller plasma sizes), show that it is possible to build power reactors which are not much larger than the TFTR now being built.

A long-range objective beyond TFTR is the design and construction of an economical EPR, but the transition directly from one to the other may be technologically ambitious. However, because of the pressing need to operate at a higher power density (smaller machine), an interim design of an ignition reactur beyond TFTR is being considered as The Next Step ('INS).

TNS, an ignition device extrapolative to a power reactor, was actively pursued in FY 1977 by two laboratory teams with industrial support. Their objectives, established by the Development and Technology Program, included defining the proper sequence of design, $R \& D$, and construc-

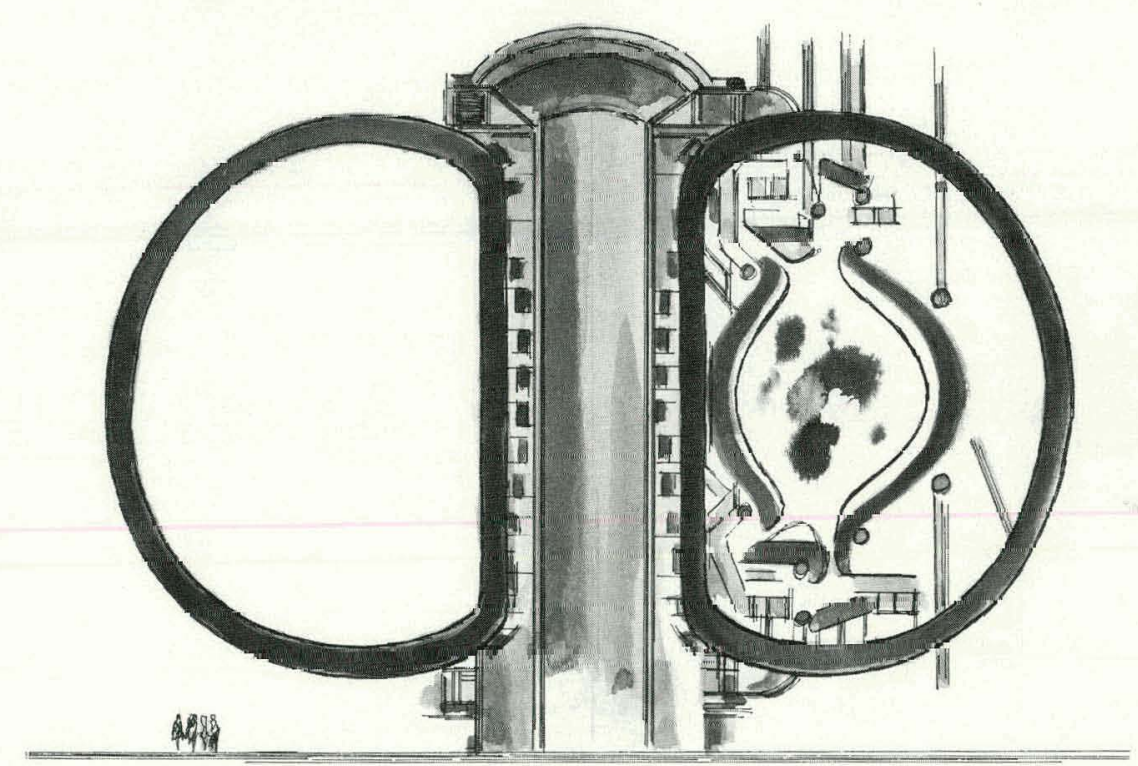

1975

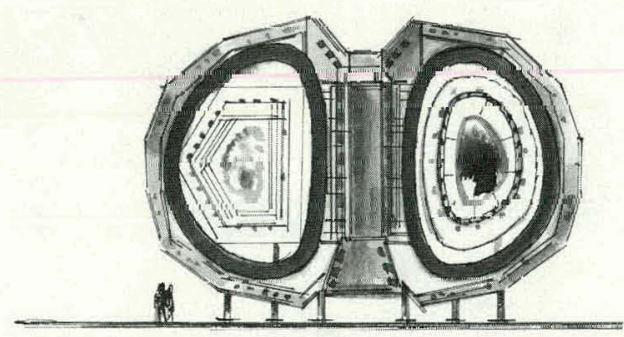

1977

A commercial reactor concept based on 1975 achievements in physics resulted in this excessively large and expensive design. Analysis indicated that if power density could be improved further, size and cost would diminish significantly. This gave impetus to new. technical developments which resulted in the much smaller and less expensive concept pictured on the right. 
tion elements to support the orderly development and cnnstruction of a TNS; identification of all critical R\&D tasks; identification of the necessary schedule for TNS operation in the mid to late 1980's; and the identification of budgets for these objectives.

Another evolutionary approach leading to a tokamak EPR is the high field compact tokamak reactor. This concept was motivated by recent experimental studies of plasma confinement which show that the energy confinement time increases with increasing density. The implication of this scaling is that ignition can be obtained in a compact tokamak by utilizing high ficld toroidal coils (15 tesla). During 1977 the plasma physics and engineering aspects of the high field compact tokamak power reactor were studied.

While the EPR/TNS studies continued to narrow the objectives for the next generation tokamak, other studies were initiated working back from the ultimate objective - a commercial fusion power reactor. One investigation in 1976 yielded the concept of a cluster tokamak fusion power plant consisting of multiple (3-5) tokamak reactor units sharing a number of common elements, such as the power supplies for driving the plasma current and the power supplies which provide the plasma with auxiliary heating. Each reactor unit would produce about 500-1000 MWe of output power.

Finally, during 1977, the engineering, technological and economic implications of a plan were developed for demonstrating in this century the commercial feasibility of fusion power. A three-phase program was recommended: (1) ignition demonstration; (2) power technology demonstration; and (3) commercial prototype demonstration. The thrust of this plan is that a committed site and facility should be developed with all due speed for sequential demonstration of these three phases.

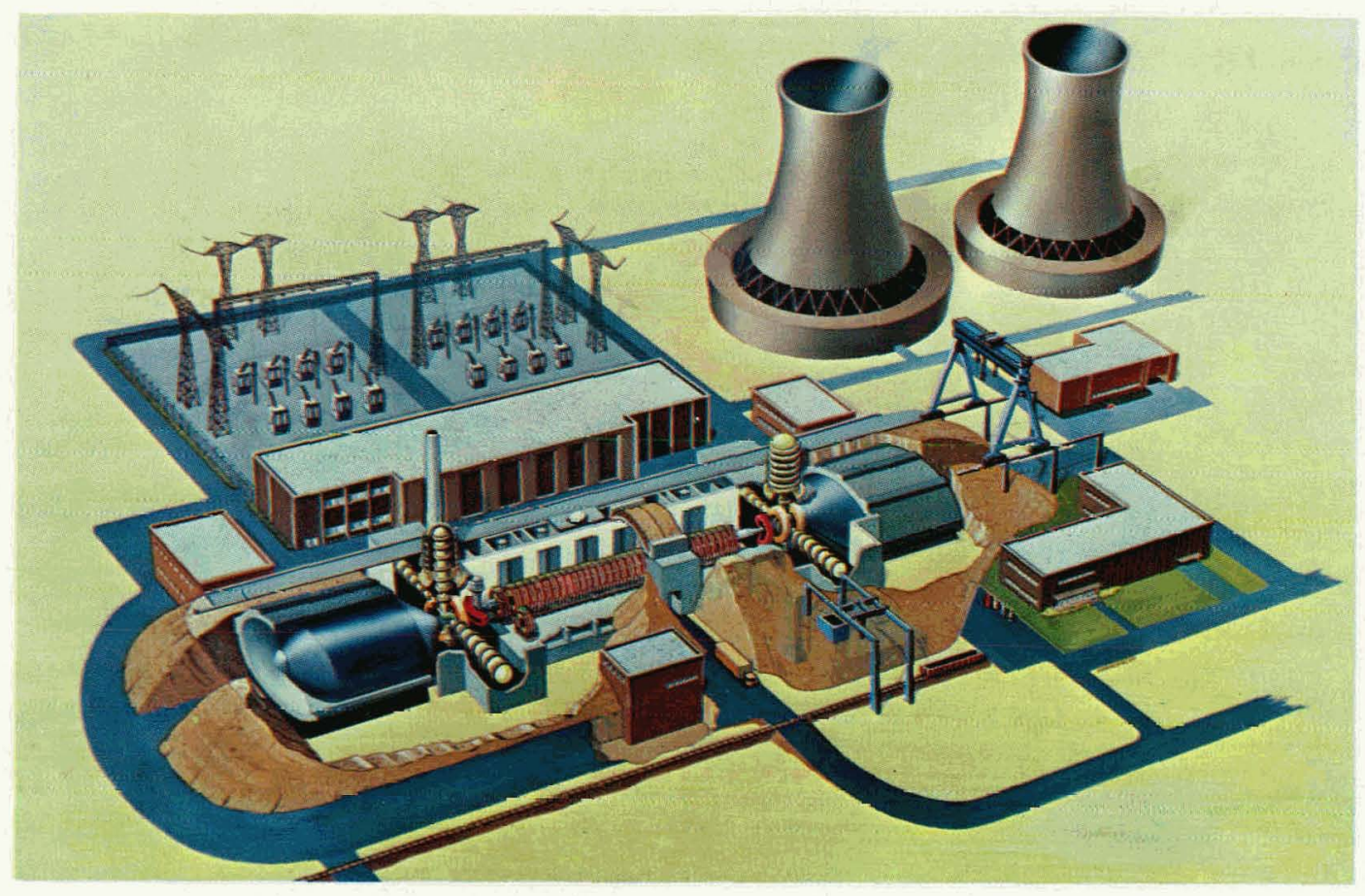

This tandem mirror reactor evolved from earlier studies identifying new concepts to eliminate end losses. This type of conceptual design is a low-cost way of evaluating new systems. It provents premature commitments to questionable approaches and guides the research and development activity needed to assure success. 


\section{Mirrors}

During FY 1976 a conceptual mirror fusion reactor design was completed aimed at determining technical feasibility and costs. The design featured a steady-state neutral-beam sustained plasma confined in a magnetic well formed by a Yin Yang magnetic configuration. However, the end losses were so high that Q-enhancement (reduced end losses relative to total power produced) was necessary to make the mirror reactor economical.

Several candidates for Q-enhancement were studied. A tandem mirror study in 1977 offered a concept incorporating end-plugging magnets and modularized intermediate sections to vary the power output of the machine with length. Partly because of improved economic and technical design features, a "proof-of-principle" tandem mirror experiment was approved for fabrication at Lawrence Livermore Laboratory.

Studies were also conducted to solve problems with a field reversal mirror concept, which was also a candidate for Q-enhancement. This activity was complementary to experimental studies of field reversal conducted on an existing $2 \mathrm{X} 11 \mathrm{~B}$ mirror device at the same site.

\section{Subsystcm Developnuent}

One subsystem development of the highest priority is that of the tritium fuel cycle and control. 'l'he radioactive isotope tritium is a necessary fuel for deuterium-tritium fusion reactors. Ultimately, tritium will be bred from neutron-activated lithium and will be returned to the fueling cycles. In the near-term, it will be recovered trom traps (getters) within the vacuum pumping system.

The tritium technology development effort consists of the following four-point program:

- Tritium Systems Test Assembly, scheduled to operate in 1981, will accelerate development of the closed fuel cycle recovery system and demonstrate the handling of large tritium inventories in fusion reactor-like systems with minimal environmental and safety effects.
- Lithium Processing Test Loop will demonstrate recovery and control of hydrogen isotopes and impurities from liquid lithium.

- Experimental studies to remove tritium from inert gases by metal getters.

- Extraction of tritium from solid lithium compounds.

Another critical fusion reactor subsystem is the blanket and shield. The blanket is considered to be the entire structure from the first wall to llie superconducting magnets. Its development problems must be solved if fusion reactors are to become realitics.

The functions of the blanket are to: (1) provide a region where the neutrons emanating from the plasma are converted into heat; (2) serve as a site to breed tritium used in the reaction; and (3) act as a shield to protect the magnets from radiation which could lead to a loss of their superconductivity.

Because these functions are so varied, the most critical problems to be overcome in achieving a successful blanket design deal with the selection and qualification of its constituent materials.

Materials must be assessed for their neutronics behavior, resistance to radiation damage, tritium proccssing characteristics, static and dynamic properties at operating temperatures, compatibility with each other, fabricability and availability. Blanket studies to date have considered "solid" and "liquid" concepts, using solid lithium compounds or molten litliium or lithium salts.

A common problem to all concepts is how to recover the Litium without significant build-ups within the blanket. Compatibility of molten salts and compounds with the various structural materials has yet to ho investigated in depth and use of molten lithium presents severe pumping problems. For solid systems, sintering of small particles must be minimized to prevent tritium build-up, and a neutron multiplier such as beryllium may be required 
to increase neutron heating. Because of the limited availability of U.S. supplies of beryllium, other multipliers, such as lead, may be used.

There has yet to be an evaluation of the blanket structural elements in an actual or simulated environment of high radiation fluxes, pulsed thermal and mechanical loads and exposure to corroding media. Extensive testing lies ahead to qualify materials.
Since blankets are not required for test reactors (e.g., PLT and TFTR), work in this field is presently limited to conceptual studies of blanket systems and radiation resistant alloy development. However, a good start has been made toward defining the technical requirements and problems which will be faced in fusion power. Moreover, design and analysis have begun on several blanket configurations.

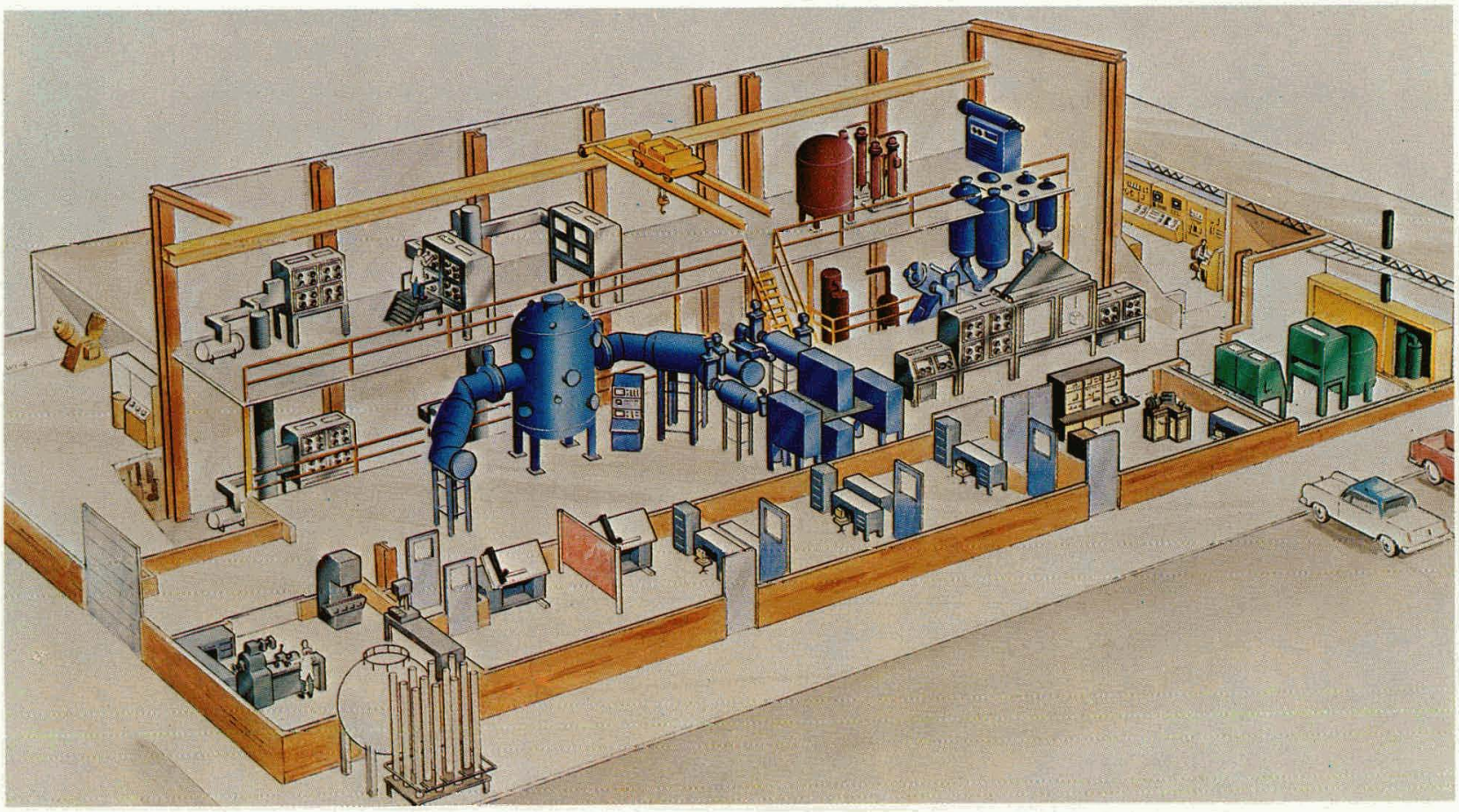

First generation reactors will use tritium, a radioactive isotope of hydrogen, as one of the fuel components. This Tritium Systems Test Assembly will be operational in 1981 at the Los Alamos Scientific Laboratories to accelerate tritium technology development, leading to safer and more efficieri operation of reactors. 
Plasma engincering addresses all technology problems associated with maintaining the fusion process, which can be divided into three basic sequential events:

Fueling - The fuel must be introduced into a chamber, which has been pumped down to an ultrahigh vacuum to remove impurities, such as air and chamber wall outgassing products.

Heating The fuel must be heated to high temperatures as a plasma so it can be confined within a magnetic field and heated further.

Impurity The by-products, consisting of Control helium, deuterium, tritium and other impurities must be exhausted or pumped from the plasma chamber for clean-up and recycling of the unused fuel.

\section{FUELING}

The ultimate objective in fueling development is to devise the most economical and practical method for continuous resupply of fuel to a net power reactor. Deuterium (D) and tritium (T) are the fuels planned for first-generation power reactors because they react much more readily than do other fuels. There are several ways to fuel a reactor: gas puffing, pellet injection, and neutral beam injection.

Gas puffing, in which pressurized gas is injected in short bursts, was successfully used for the Princeton Large Torus (PLT). During a onehalf second shot, the gas density profiles needed for the machine's short pulse operation were built up and maintained.

Pellet injection involves high velocity injection of frozen fuel pcllets, such as a mixture of deuterium and tritium. This method was developed by the University of Illinois and ORNL in 1976 and tried on the Oak Ridge Tokamak "TSX" with injection velocities up to $500 \mathrm{mctcrs} / \mathrm{sccond}$ in March 1978. Pellet injections of 1,000-2,000 meters/second may be adequate to fuel full-scalc power reactors and are expected to be developed and tested within the next four ycars.

Neutral beams are mainly sources of heat for the plasmas. (This aspect is discussed further

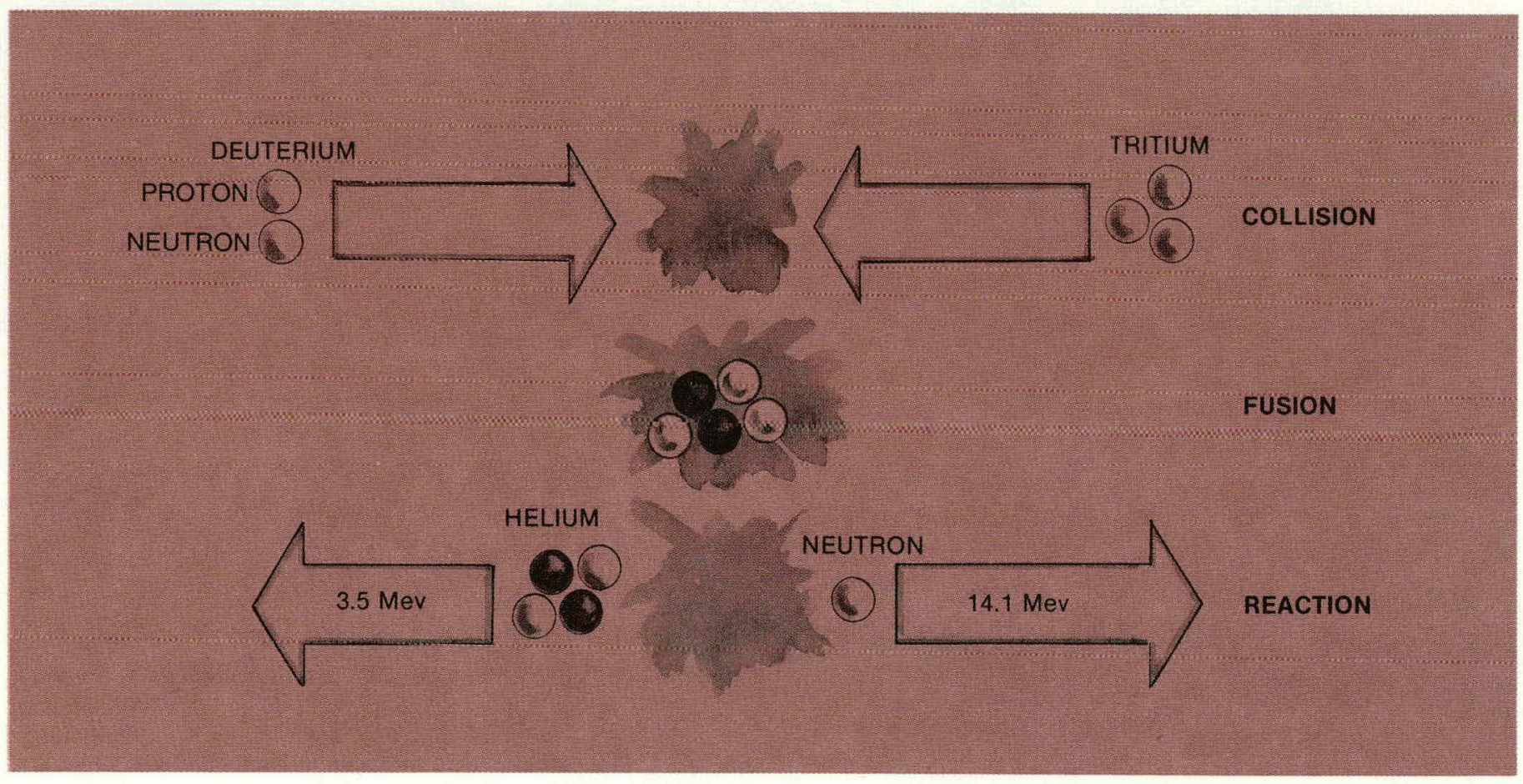

Deuterium and tritium react to form helium nuclei and high-energy neutrons. Because the mass of the reactants is less than the initial mass of the deuterium and tritium, energy is released in accordance with Einstein's equation, $E=M C^{2}$, where " $M$ " is the mass change and " $C$ " is the velocity of light. After the fusion reaction, each helium nucleus has an energy value of 3.5 million electron volts (Mev) and each neutron $14.1 \mathrm{Mev}$. The highly energetic neutrons will heat blankets surrounding the reactor. The heat can then be removed from the blankets and used to produce steam for the conventional steam turbine-generator cycle. 
under "Heating Technology.") Their utility for fueling is somewhat constrained to systems which require continued heating to sustain plasma operation. The fueling needs of future devices, such as the Experimental Power Reactor (EPR) and demonstration reactors, will be much more demanding since they are planned for longer burn periods and higher burn-up rates. For example, calculations show that to get penetration, pellet injection velocities of several thousand meters per second will be necessary. Injection tests at these velocities are planned for mid-1978 on the PLT and in 1979 on the Poloidal Divertor Experiment using the ORNL Centrifuge pellet injector.

\section{VACUUM TECHNOLOGY}

Ultrahigh vacuum is required for the reactor chamber (into which tritium and deuterium fuel is introduced) and for the neutral beam injection system. Most materials give up entrapped gases at low pressures. To offset the high rates at which this outgassing can occur, vacuum pumps with high pumping rates must be employed to maintain about $10^{-8}$ torr $(.00000001$ millimeters of mercury) in these large containers. The neutral beam injection systems need even higher pumping speeds because the injector, during operation, releases substantial amounts of gas which must be captured by the pumping system.

To meet such demands, an assortment of pumps will be used ranging from the roughing pumps that reduce chamber pressure to around $10^{-4}$ torr, to high rate cryopumps that trap any remaining gases on panels as cold as $-269^{\circ} \mathrm{C}$, only $4^{\circ}$ above absolute zero.

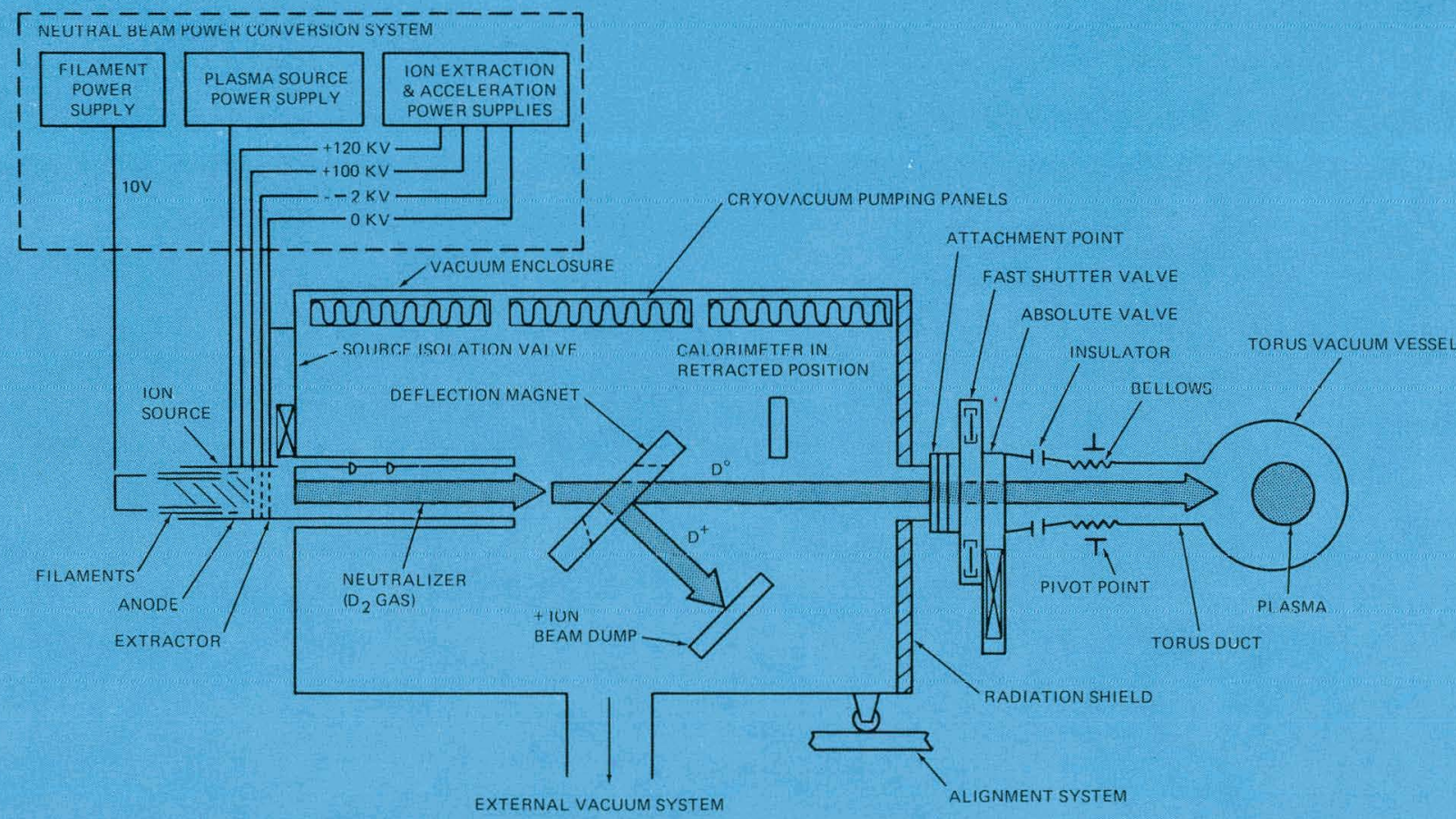

BEAMLINE FUNCTIONAL SCHEMATIC

Neutral Beam Injection Systems, shown schematically, are used both to supply additional fuel and heat the plasma. Before starting, the enclosing vacuum chamber is pumped down. Next,deuterium atoms are stripped of electrons and electrically accelerated to high velocity. They are then neutralized by electron exchange with a low energy gas cloud to allow undeflected entry through the magnetic field surrounding the plasma in the reactor vessel. Magnets deflect the unneutralized particles and absorb them in a beam dump. Excess low energy neutrals are trapped on cryopanels. 
Cryopumps use the extremely low temperatures of cryogenic fluids, such as liquid helium, either to condense particles on the pump's surfaces (cryocondensation) or to capture them within a sieve material (cryosorption). Because of the demanding requirements of the Magnetic Fusion Energy Program, further development work is under way to understand fully the performance of first generation cryopumps. Recent achievements by Oak Ridge National Laboratory, Lawrence Livermore Laboratory and Brookhaven National Laboratory include:

Cryocondensation,

- The behavior of cryogenic hydrogen in large cryopumps is now understood better. Hydrogen saturation and degassing characteristics of the cryopanels were determined to ensure safety when returning to normal pressure (hydrogen and air can form an explosive mixture).

- Large cryopumps were successfully operated in neutral beam injection systems.
- The ability to cryotrap helium and hydrogen on large panels was tested and evaluated, and cryopumping data for helium and hydrogen isotope mixtures were obtained.

\section{Cryosorption}

- The hydrogen pumping speed of small cryosieves cooled with helium gas was determined.

- A large cryosorption panel was designed and initial construction begun for operation at about $-260^{\circ} \mathrm{C}$.

\section{HF.ATING TFCHNOI,OGY}

Plasmas can be heated by applying various types of external energy which is absorbed by the plasma particles. Tokamak-type machines make use of an ohmic heating $(\mathrm{OH})$ coil wound around the plasma area. The coil serves as the primary of an electrical transformcr and the plasma itself becomes a shorted-turn secondary winding. $\Lambda$ rapidly changing electrical current in

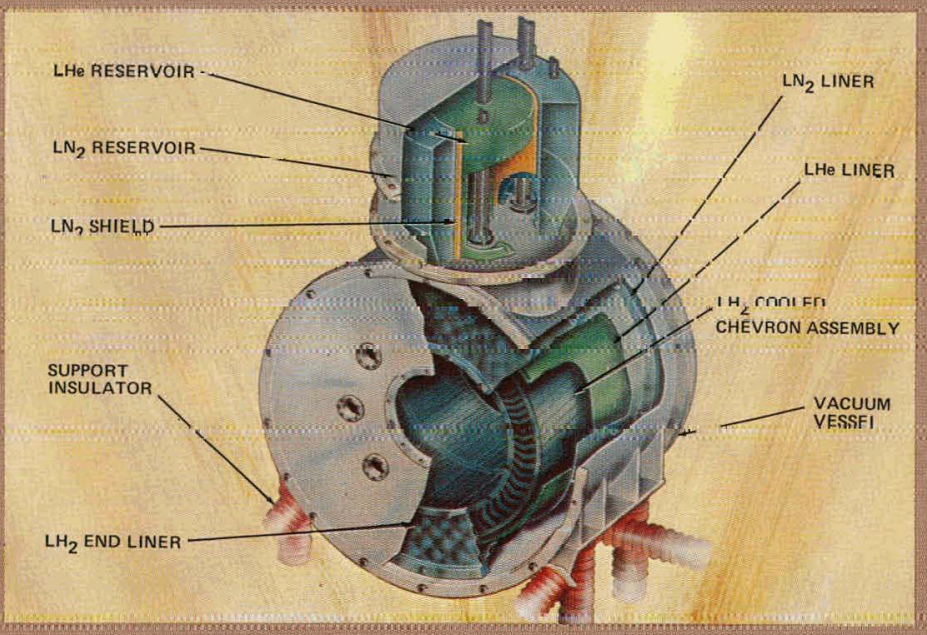

Creuting the vacuums for neutral beum systems und the reuctor vessel requires sophisticated equipment. (hrapumps coaled by, liquid helium to $-25^{\circ} \mathrm{C}$ ( 40 above absolute zern) are needed to trap stray hydrogen isotopes. 10 shield the helum from room iemperuiure losses, llyuld niltrogen ai $-190^{\circ} \mathrm{C}$ surround's the -2690 Chelium. The pump illustrated has performed beyond design specification and gives contidence that demanding vacuum requirements will be met.

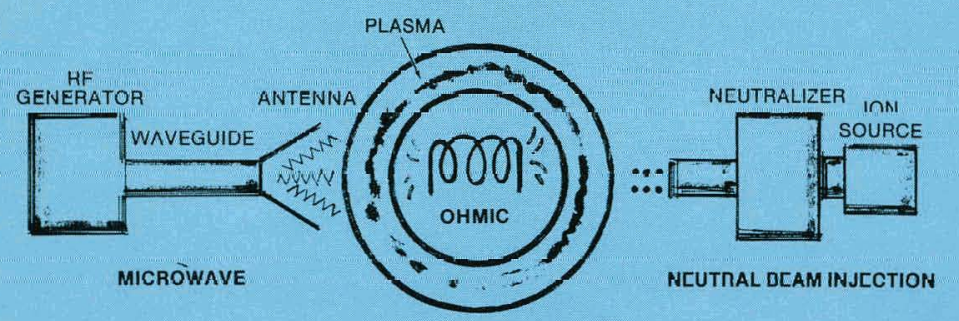

PRIMARY METHODS OF HEATING PLASMAS
Various combinations of the three heating methods shown can be used to raise plasma temperature Fxperiments surh as the Flmn Bumpy Torus at Oak Ridge use high power radio frequency. Surne tokurruk ard rritror devices use all three in the quest for the ultrahigh temperatures needed for "ignition" - the point where the reaction can be sustained without external energy supplies. 
the $\mathrm{OH}$ coil induces a huge current flow in the plasma which heats it up. This method is convenient but becomes somewhat ineffective (due to loss of plasma electrical resistivity) before desired plasma temperatures can be achieved.

Neutral beam injection is a method of highlevel heating in which the plasma is penetrated with intense, electrically neutral beams of atoms. In 1978, injection levels equivalent to 50 million ${ }^{\circ} \mathrm{C}$ will be possible with the PLT at the Princeton Plasma Physics Laboratory. Moreover, the Tokamak Fusion Test Reactor (TFTR) beam injectors under construction at Princeton, are expected to develop higher temperatures which, for the first time, will produce about as much energy as was used to create the reaction.

Plasmas can also be heated by radio frequency (rf) power in a manner resembling the operation of a microwave heating oven. Current development in this area is associated primarily with a 200,000 -watt microwave gyroklystron device to be used in heating studies on confinement devices at Oak Ridge National Laboratory.

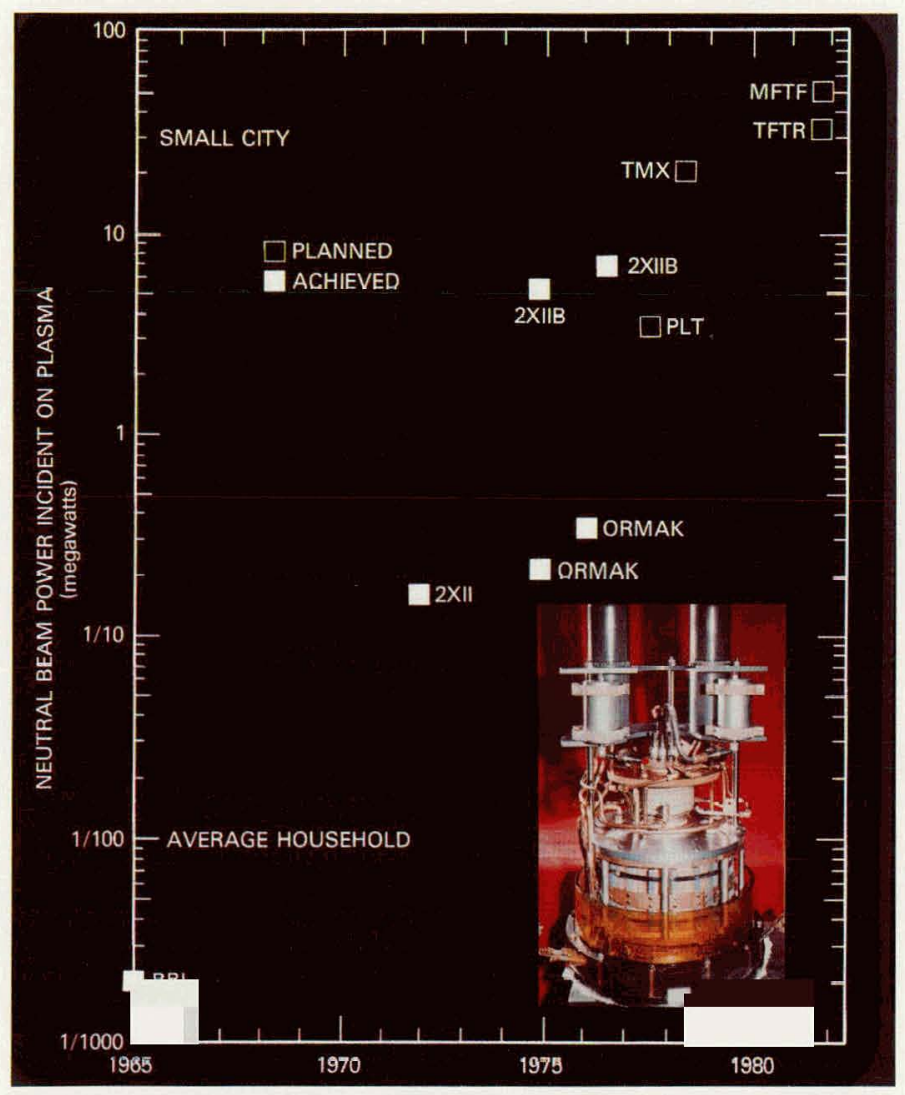

Future work in plasma heating systems will concentrate on improving efficiency and reliability. To this end, several concurrent research and development programs are seeking new data related to:

- Direct energy converters, which can increase the efficiency of neutral beam injectors by recovering energy from unneutralized ions. A program on direct energy conversion is in progress at Lawrence Livermore Laboratory, California, to develop workable methods and hardware for ion beam and plasma flow applications.

- Negative ion sources, which could overcome the marked inefficiency of positive ion sources above 150 kilovolts.

- Improvements in ion sources; reliable multi-megawatt electrical power systems; and high power density beam stops and calorimeters.

- Development of megawatt microwave components and devices such as gyroklystrons, waveguides, and couplers.

Demonstrated neutral beams with millions of watts of heating power show that progress is steady toward providing the heating power required for fusion reactors. However, the large power drain emphasizes the importance of $D \& T$ efforts to improve their efficiency. 
Large magnetic fields are needed to confine and control the ultrahot plasmas in fusion reactors. Generating these fields requires large amounts of electrical energy when conventional conductor materials, such as copper, are used in the electromagnet windings; in fact, the energy needed is so great that net power production could be jeopardized.

Although it has been necessary and economical to use electromagnets with conventional conductors to confirm theories and develop interim fusion hardware, magnets that consume significantly smaller amounts of energy will be needed for future fusion power facilities. Fortunately, a potential solution was discovered many years ago, when it was found that certain materials, such as niobium-titanium (NbTi) and niobium-tin $\left(\mathrm{Nb}_{3} \mathrm{Sn}\right)$, offered no resistance to electric current when they were cooled to cryogenic temperatures (approximately $-260^{\circ} \mathrm{C}$ ). These materials are called superconductors and although they require a nominal amount of energy to supercool them, they consume negligible energy due to electrical resistance losses. Although the principles of superconducting magnets are well known, a number of difficult engineering problems must be solved before they will be ready for large reactor applications.

To meet this need the Magnetic Systems Branch has the following activities underway at various technical centers around the country:

\section{SUPERCONDUCTING MAGNET DEVELOPMENT PROGRAM}

\begin{tabular}{|c|l|}
\hline MAIN STUDY OBJECTIVES & WORK BEING PERFORMED \\
\hline $\begin{array}{c}\text { Develop analytical and } \\
\text { physical tools }\end{array}$ & $\begin{array}{c}\text { - Develop computer codes to solve complex electromagnetic and thermal problems } \\
\text { associated with magnet design. } \\
\text { - Generate techniques for structural analysis of composite materials. } \\
\text { - Study relative merits of all available cooling methods. } \\
\text { - Design and build facilities to test various superconductors fabricated by industry. }\end{array}$ \\
\hline $\begin{array}{c}\text { Develop and improve } \\
\text { performance of } \\
\text { supcrconductors }\end{array}$ & $\begin{array}{l}\text { - Evaluate subcooled niobium-titanium (NbTi) for high magnetic field use. } \\
\text { - Study conditions influencing characteristics of niobium-tin (Nb } 3 \text { Sn) to reduce handling } \\
\text { difficulties and enhance performance. } \\
\text { - Improve and develop new fabrication techniques, such as hydrostatis: extrusinn to } \\
\text { redice costs and produce a more reliable conductor. } \\
\text { - Devclop thermodynamic and stability criteria for various conductors and cooling methods. }\end{array}$ \\
\hline $\begin{array}{c}\text { Fabricate and test large size } \\
\text { magnets (Large Coil Program) }\end{array}$ & $\begin{array}{l}\text { - Develop design and manufacturing technology for toroidal field coils similar to those } \\
\text { intended for 1980's generation of experimental tokamaks. }\end{array}$ \\
\hline
\end{tabular}

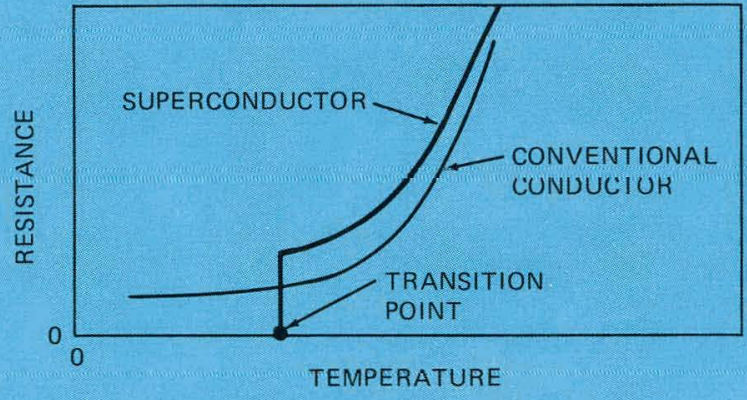

Superconductors vs Conventional Conductors

As conventional conductors are cooled, their resistance to electric current decreases but remains finite. As superconductors approach absolute zero temperature, their resistance suddenly disappears. Expressed in practical terms, the conventional conductors in the TFTR toroidal field coils will require about 400 million watts of power when operating. If superconducting coils were used, this power drain could be reduced to about 1 million watts, almost all of which would be used for refrigeration to supercool the coils.

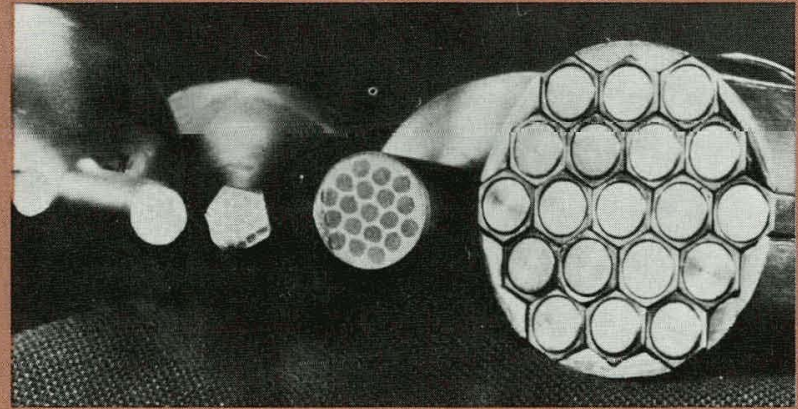

Developments such as the hydrostatic extrusion of multifilamentary wire shown here will reduce cost and increase reliability of future magnetic systems. The superconductors are first assembled in a matrix material and then successfully extruded through dies to achieve the desired smaller size and high quality. 
The first two development programs are now generating much of the technology for the Large Coil Program located at Oak Ridge National Laboratory, Oak Ridge, Tennessee. This program is using the experience of U.S. industry to design and construct a group of large coils based on alternative design concepts. These concepts propose different methods of winding, cooling and thermal stabilization. For example, cooling could be achieved by submerging the coils in a pool of liquid helium or by force-flowing supercritical helium around each conductor. The various design concepts have theoretical advantages and disadvantages which will be evaluated during testing.

Three companies were awarded contracts early in 1977 to design and build these magnets. The Oak Ridge National Laboratory will construct the facility to test these coils.

Under an agreement between the U.S. and the International Energy Agency a number of foreign countries will design and build superconducting magnets and provide them for testing along with the U.S. magnets in the Large Coil Test Facility.

The results of this test program are expected to permit rational decisions to be made regarding their use in future reactors designed to produce net electric power.

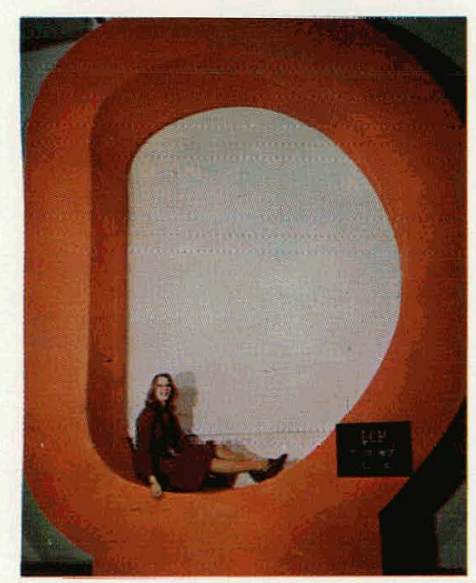

Advances in superconducting technology have progressed to the point where large superconducting magnets can be designed, built, and tested. When completed, each large. coil shown will use 40 tons of copper, steel, and superconductor. Next generation reactors will use 16 to 20 such coils and will significantly advance the goal of achieving net energy from fusion.
Superconducting technology has other applications of importance to the fusion program. For example, current fusion devices use complex methods to store energy needed to pulse the various electrical demand systems. With superconducting homopolar generators now under development both fast and slow pulsed energy transfers can be accomplished more efficiently.

Three superconducting storage coils, specially designed for rapid discharge of stored energy to produce high power pulses, were tested at the Los Alamos Scientific Laboratory. One coil surpassed design conditions in storing 540 kilojoules of energy and producing a maximum power of 230 megawatts on rapid discharge.

Since the generation, storage and transmission of electricity is common to many subsystems in fusion devices and in conventional powerplants, many spin-off applications are anticipated. For example, resistance welding using pulsed homopolar generators developed under the magnetic fusion program is a promising technology spin-off. Four-inch pipes have been welded successfully employing a 200,000ampere current produced by a 5-megajoule homopolar. A 50 megajoule device, for which a design exists, would be able to resistance-weld 100 square inches of pipe - the size of the Alaskan pipeline - in one second!

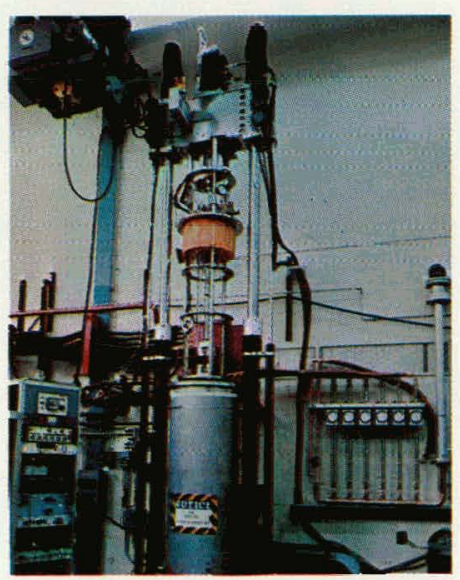

The Tensile Test Facility can test superconductors under strain in a 50,000-pound tensile test while simultaneously applying a 1.3 tesla field. It is presently being used to determine strain tolerance of multifilament $\mathrm{Nb}_{3} \mathrm{Sn}$ superconductor. 
Development and qualification of the construction materials for a successful commercial nuclear fusion power reactor involves all the technical problems of designing complex heat engines and power conversion systems, and a whole new set of challenges as well.

For example, the temperature in a typical fusion system ranges from over 100 million ${ }^{\circ} \mathrm{C}$ in the burning plasma to near absolute zero in the cryogenic magnets that confine the plasma. These extremes are encountered only a few meters apart.

To further illustrate the materials challenges:

- What material surfaces can withstand the erosive effects of the intense radiation from the burning plasma?

- How long will a reactor structure last under the radiation damage produced by the very energetic fusion neutrons?

- Which materials are capable of resisting the high stresses imposed by the powerful magnets and the sizable temperature gradients?

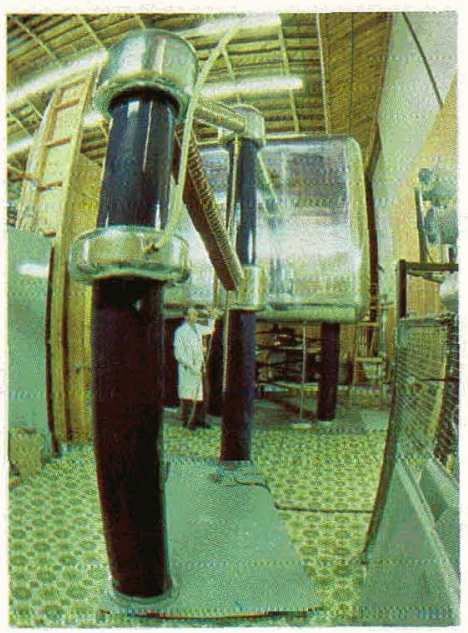

Perhaps the main challenge stems from the intense radiation composed mainly of neutrons, and atomic particles and electrons that escape the magnetic confinement. The energetic neutrons collide with atoms in the wall material and create displacement and transmutant damage to its atomic lattice structure. It is estimated that every atom in a fusion reactor first wall structure will be displaced between 10 and 20 times a year.

High energy fusion neutrons are also prolific producers of helium and hydrogen gas through the nuclear transmutation reactions that they induce in the surrounding material. This combination of displacement damage and high gas generation is a characteristic unique to fusion neutrons but not much is known about the resulting degradation of materials properties. Materials radiation test data obtained in fission reactors do not adequately describe the phenomenon. For this reason, special irradiation test facilities that provide strong sources of suffi ciently energetic neutrons are essential to a responsible program.

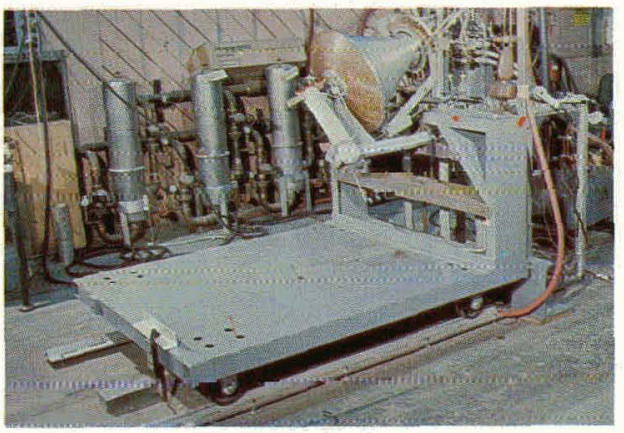

The rotating target neutron source, RTNS-II, at the Lawrence Livermore Laboratory, scheduled to become operational in March 1978, will provide the most intense source of $14 \mathrm{MeV}$ fusion neutrons in the world. It will be dedicated to materials research for the fusion energy program. The fusion neutrons are produced by bombarding a tritium-loaded target with an energetic deuteron beam from an accelerator. The tritium is contained in a thin layer of titanium cvaporated onto a copper backing. The target rotates at $5000 \mathrm{rpm}$ to reduce beam dwell time and is cooled by water flowing within channels inside the target backing to remove deposited beam energy and to prevent rapid outgassing of the tritium due to thermal diffusion through the titanium. The source is housed in a target room with 2.5 meter-thick concrete walls to provide neutron shielding. Since the high neutron fluxeswill produce substantial radioactivation in the target room, remote handling facilities are provided to replace the spent target (after 100 hours operation) and to position and align the experiment package. 
First wall surface damage also is caused by impingement of helium, deuterium and tritium atoms. The resultant action of sputtering or blistering is a leading cause of wall erosion, the products of which are principal sources of plasma contamination.

Radiation effects, especially neutron effects, tend to degrade the mechanical properties important to the lifetime of structures, such as crack growth rate, fracture toughness and fatigue life. Significant embrittlement may be produced by the helium and hydrogen gas generated internal to the structure by neutrons.

Recently, a Structural Alloy Development Program was begun to develop and evaluate materials that will withstand fusion reactor operating environments. In addition to irradiation performance problems, this program also considers the conventional aspects of materials engineering, including economics, manufacturing technology, and resource availability. system, four parallel paths are being pursued. These are:

1. Austenitic alloys, such as various stainless steels. These alloys are of interest because there is an extensive data base on their fabrication and irradiation behavior. The development program will seek to optimize composition and grain structure for the fusion environment. Although austenitics show great promise for the EPR, their resistance to temperature and radiation may not meet the demands of commercial fusion power.

2. Iron-chromium-nickel ( $\mathrm{Fe}-\mathrm{Cr}-\mathrm{Ni})$ superalloys. These alloys show good resistance to radiation and have higher strength and withstand higher temperatures than austenitic alloys. Problems to be overcome are lower ductility, more difficult fabrication; and poor compatibility with liquid metals being considered as candidates for the fusion reactor heat exchange medium.

To ensure success for interim systems, such as the EPR, as well as the ultimate commercial
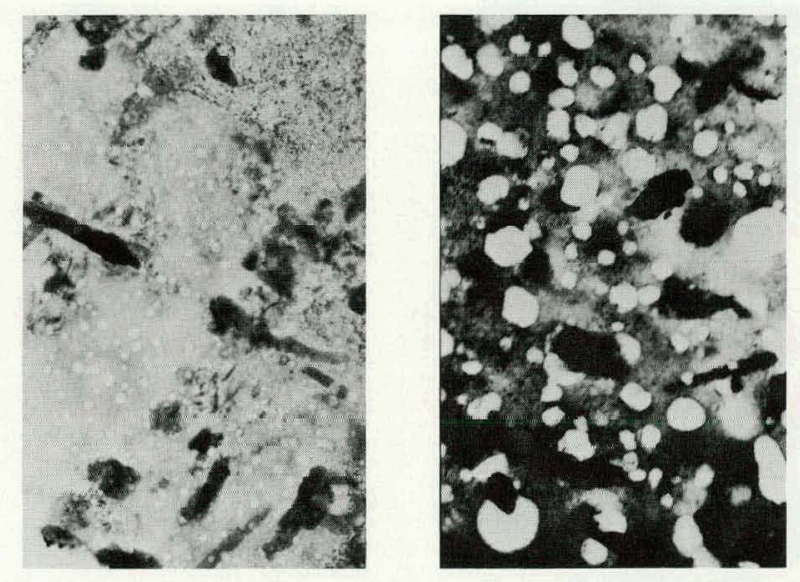

\begin{tabular}{|c|c|c|}
\cline { 2 - 3 } \multicolumn{1}{c|}{} & $\mathbf{2 0} \%$ Cold Worked & Annealed \\
\hline Swelling & $\mathbf{2} \%$ & $\mathbf{9} \%$ \\
\hline Cavities & Small & Larger \\
\hline $\begin{array}{c}\text { Grain } \\
\text { Boundaries }\end{array}$ & Free of I arge C.avities & Free of Large Cavities \\
\hline
\end{tabular}

Transmission electron micrographs showing influence of microstructure on void swelling behavior of stainless steel irradiated to fusion-like conditions.

Void swelling due to irradiation is determined by the size and concentration of induced cavities. These cavities are formed by the coalescing of atomic lattice vacancies produced in atomic displacements. For fusion radiation conditions it has been found that cold work increases cavity concentration but reduces cavity size, resulting in a net reduction in void swelling in comparison with annealed materials. This is illustrated in the accompanying microphotographs of irradiated stainless steel on which cavities appcar as approximatcly circular whitc arcas. 
3. Reactive and Refractory Metals and Alloys. This group contains the strongest candidates for reaching the materials goals for commercial fusion power, because of their high temperature behavior, promise of adequate radiation resistance, and favorable resistance to cyclic thermal stress and the associated fatigue. The drawbacks are that these alloys are difficult to fabricate and join, and are sensitive to oxidation and other contaminants.

4. New Concepts. This effort is devoted to exploration and development of innovative and composite materials, including structural ceramics, fiber structures, and ultralow radioactivation concepts. Special production techniques, low-expansion alloys and long-range ordered alloys are examples of other potential developments in this program category.
The alloy development program is supported by the coordinated activities of four task groups covering: irradiation performance; interaction between materials and the plasma; fundamental damage analysis; and special purpose materials. These task groups define problems and the specific work required to solve them.

\section{Current Progress Toward a Solution}

\section{Irradiation Testing}

Analytical and experimental study results have led to the conclusion that for nickelcontaining alloys (e.g, austenitic stainless stcels), those existing fission reactors that provide both thermal and fast neutrons can be used to produce the radiation effects characteristics of fusion neutrons. This means that the most likely structural material candidates for nearterm fusion reactors can be tested now ahead of the construction of adequate fusion neutron irradiation facilities.
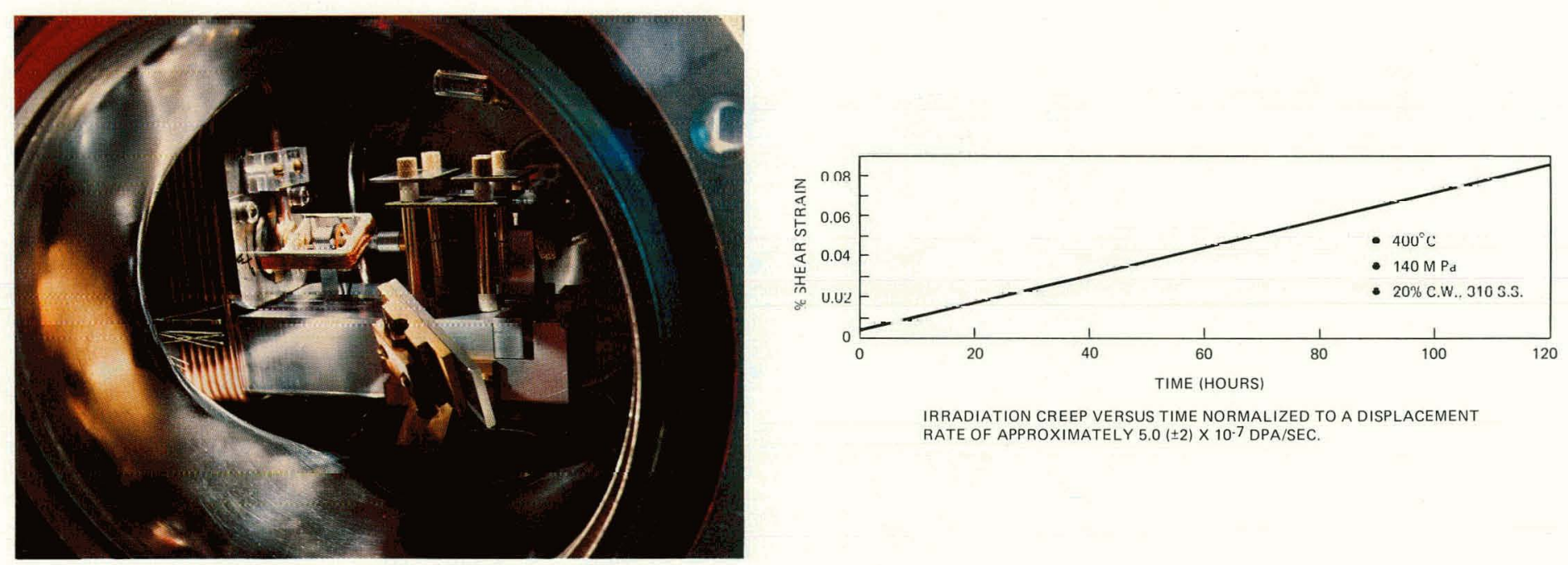

Irradiation creep is likely to be the dominant deformation mode for structural components in a fusion reactor, and must be controlled to satisfy deformation limits required by the reactor design. To advance theoretical models to the point where radiation creep can be predicted adequately, and creep-resistant alloys can be developed, a broader experimental data base is needed. The photograph shows a torsion creep test fixture set up to measure irradiation creep induced by high energy proton bombardment. (Previous work has shown that irradiation with energetic protons can produce an adequate simulation of neutron-induced creep.) Typical results obtained with this experimental setup for a steel specimen are shown in the graph. A constant shear stress applied during a continuous proton bombardment is seen to produce a linear growth in shear deformation during the first two-thirds of the experiment, indicating that in this domain the irradiation creep depends linearly on atomic displacement. Beyond a certain accumulated displacement level the curve becomes slightly supralinear, suggesting that the creep rate begins to grow with atomic displacement. 


\section{Surface Interactions}

The results of experimental studies show that neutron sputtering is insignificant compared to helium and hydrogen isotope sputtering. Furthermore, although blister formation by surface implantation of helium and hydrogen is important, it appears to be less severe for the energy distributions of particles found in a reactor than in tests with single energy particles. In addition, blister formation may be further reduced by controlling the temperature and the grain structure of first wall material. An active program is seeking to develop wall coatings of low atomic number materials which should display even higher resistance to sputtering.
A broad technical assessment of fusion reactor materials has shown how the choice of materials can affect the cost of electricity produced from a fusion power reactor. Generally, design and economic analyses show that the economics will be influenced most by firstwall lifetime.

Much work remains to be done in materials science and technology before commercial fusion power can become a reality. However, the road to this goal has been mapped. Specific achievements to date have already contributed to a much better understanding of the behavior of materials in a fusion environment.
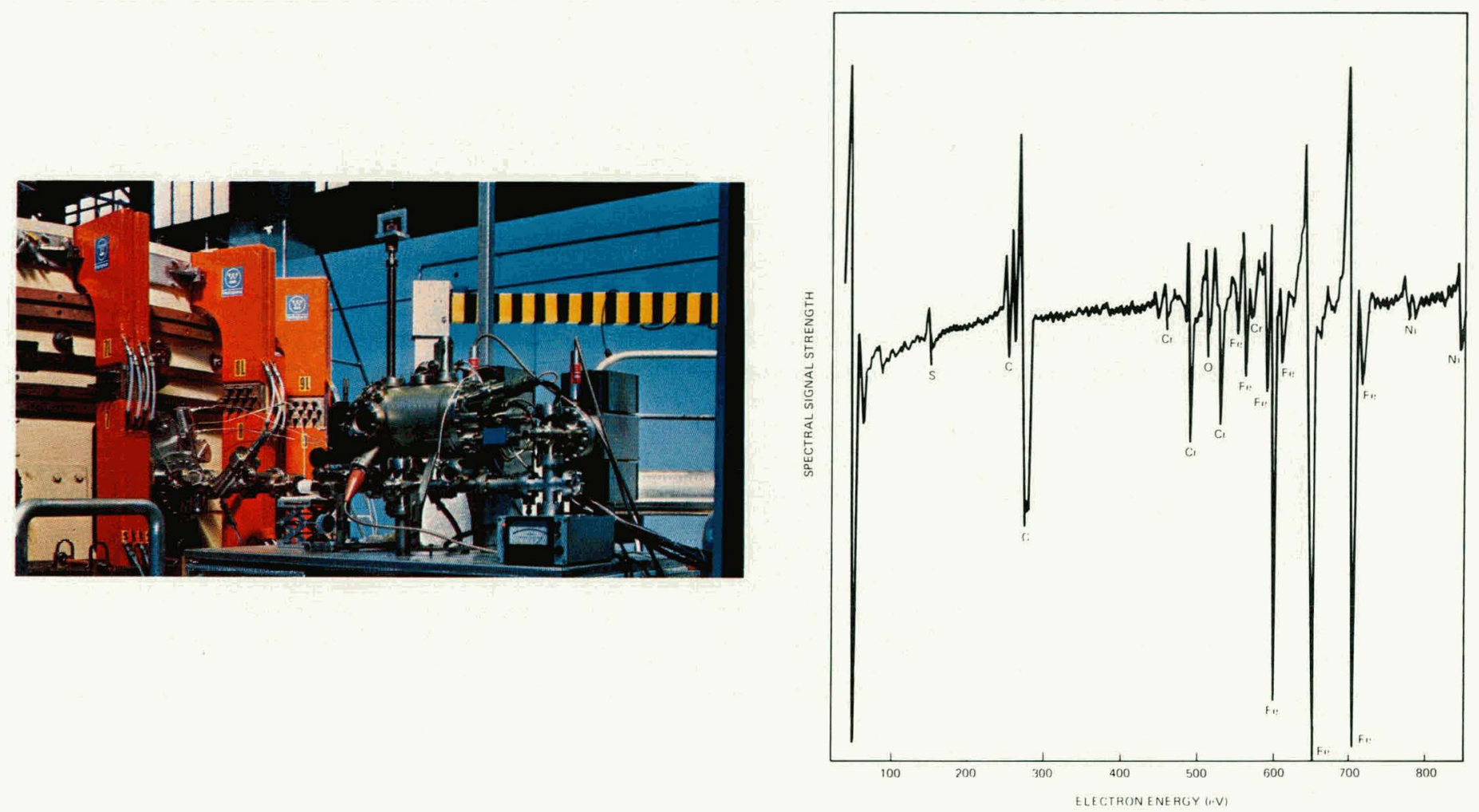

The Impurity Study Experiment (ISX) is dedicated to the study of surface impurity and plasma impurity problems. It consists of a tokamak and an external analysis station as shown in the photograph. The analysis system contains a high-resolution Auger electron spectrometer to provide quantitative elemental surface analysis, and a thermal desorption apparatus to quantitatively monitor gas evolution from sample surfaces. The analysis system is connected to the tokamak plasma chamber through a remotely operated sample transfer system. This permits samples that have been exposed to individual plasma shots at precisely monitored positions to be transferred out of the plasma chamber for analysis while tokamak operation continues. The graph shows a typical Auger spectrum for a sample of the ISX stainless steel wall that was exposed to a plasma test shot in the ISX tokamak. Most of the peaks in the spectrum correspond to the elements that comprise the stainless steel ( $\mathrm{Fe}, \mathrm{Cr}$, and $\mathrm{Ni}$ ); the principal contaminant is seen to be carbon. Except for hydrogen, the Auger analysis provides a complete description of the surface composition of a sample, and thus gives a measurement of the impurities absorbed from the plasma. 


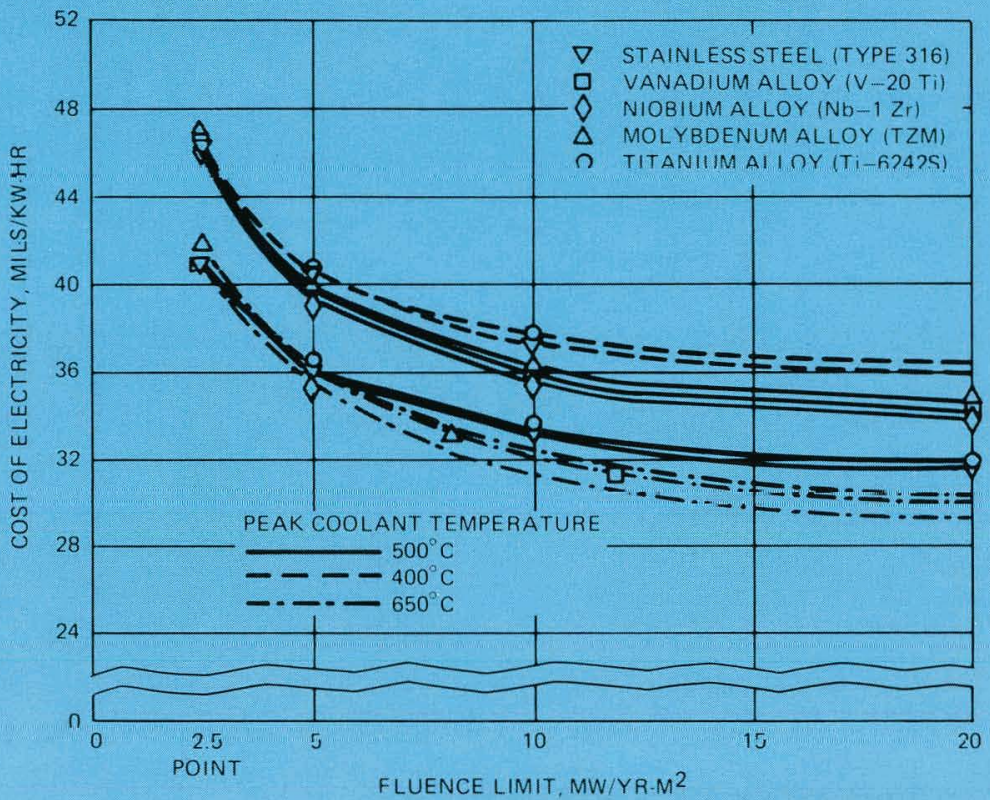

Computer-based parametric studies of fusion power economics are providing important initial insights on how the cost of fusion power is influenced by various material properties and reactor operating conditions.

The first wall component life and coolant temperature are important factors affecting reactor performance and cost. For example, the periodic maintenance of this structure will be costly and time consuming. To reduce maintenance, one would like the structure to last as long as possible.

Higher coolant temperature results in higher conversion efficiency. However, the possible efficiency gain is in part offset by the higher material costs for high temperature materials. The relationship between component life and coolant temperature is shown for material in the first wall and blanket structure. (Outside the region, the use of lower cost materials such as stainless steel or titanium has been assumed.) With respect to component life, there is a strong economic incentive for increased wall life, if life is short. However, after about 10-15 $M W$-yrs $/ \mathrm{m}^{2}$ the benefit of additional wall life increases are greatly diminished. The effect of wall life on the cost of electricity is independent of peak coolant temperature.

The largest economic leverage for the rejractory metals results from bolth ine poleni ial capability of operating at a higher allowable coolant temperature and the potential for loriger life. A peak coolant temperature of $500^{\circ} \mathrm{C}$ for the refractory metals produces a lower cost of electricity than a $400^{\circ} \mathrm{C}$ coolant temperature for stainless steel or titanium, providing wall life is $>3 \mathrm{MW}$-yrs $/ \mathrm{m}^{2}$; the economic margin increases with increasing life. However, if the life of stainless steel or titanium is about $9 \mathrm{MW}$-yrs $/ \mathrm{m}^{2}$ or greater and the peak coolant temperature is fixed at $500^{\circ} \mathrm{C}$, there is no economic payoff for the refractory metals regardless of life. On the other hand if vanadium could operate with a peak coolant temperature of $650^{\circ} \mathrm{C}$ and have a life of $20 \mathrm{MW}-\mathrm{yrs} / \mathrm{m}^{2}$, a $7 \mathrm{mil} / \mathrm{kw}-\mathrm{hr}$ (21\%) savings in the cost of electricity results when compared to stainless steel or titanium operated at a peak coolant temperature of $400^{\circ} \mathrm{C}$ and with a life of $10 \mathrm{MW}-\mathrm{yrs} / \mathrm{m}^{2}$. Life and peak coolant temperatures remain to be resolved. 

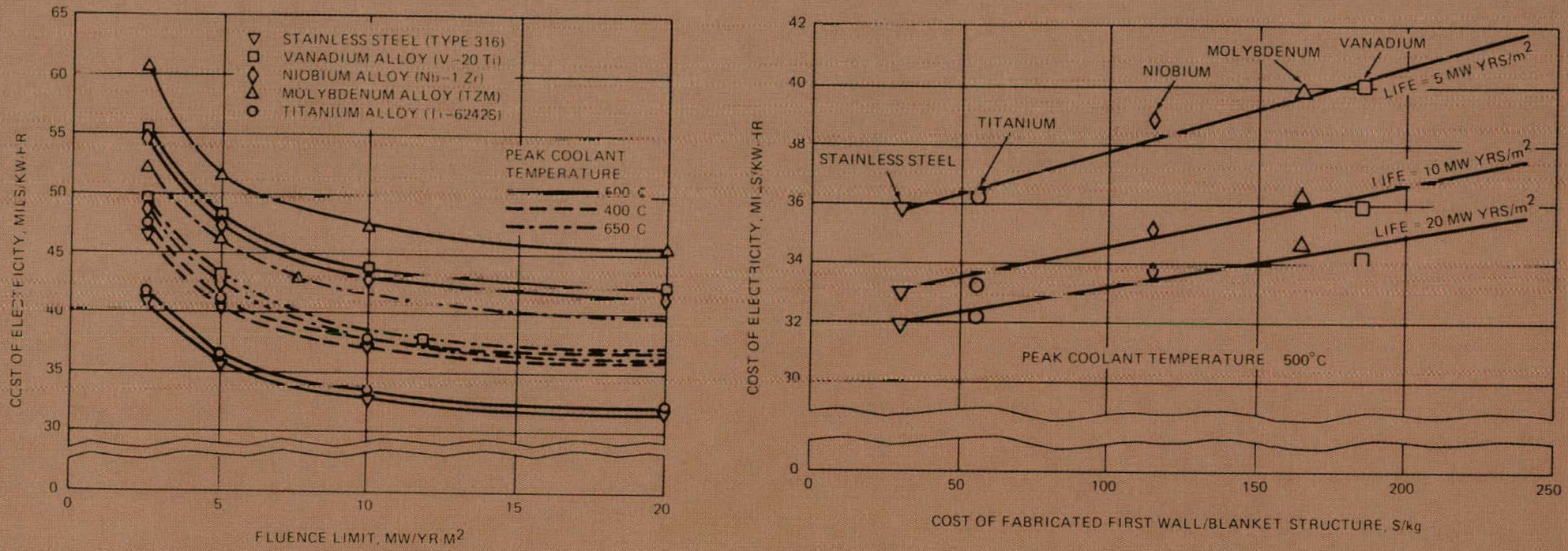

The use of dissimilar metals in the same coolant loop may lead to contamination or corrosion problems. It may therefore be necessary to use the same structural material throughout the primary coolant loop including first wall, blanket, piping, first heat exchanger, dump tanks, valves, etc. This extended use of refractory metals significantly increases the cost of electricity, as shown on the left. This increased cost is only recovered, relative to the use of stainless steel or titanium, for a very narrow set of operating conditions. These conditions require stainless steel or titanium structures to operate with a $400^{\circ} \mathrm{C}$ coolant and have a component life of $<5 \mathrm{MW}-\mathrm{yrs} / \mathrm{m}^{2}$ and the refractory metals to operate at $650^{\circ} \mathrm{C}$ and have a life of $>10 \mathrm{MW}-\mathrm{yrs} / \mathrm{m}^{2}$.

The relationship between the cost of electricity and the cost of fabricated first wall/ blanket components is shown on the right for various wall lives. This relationship is for a noncircular tokamak reactor having an average wall loading of $2.6 \mathrm{MW} / \mathrm{m}^{2}$, a capacity of $500 \mathrm{MW}$ th and a plasma height-to-width ratio of 2.0. The cost spread between stainless steel and the most expensive refractory metal, vanadium is $\$ 155 / \mathrm{kg}$, or, in terms of reactor system performance, about $2.5 \mathrm{mils} / \mathrm{kW}$-hr. Therefore, it can be concluded that the fabricated first wall and blanket part cost has a moderate impact upon the commercial fusion reactor performance (cost of electricity). However, a higher fabricated part cost for the refractory metals can be offset by higher operating temperature or long component life .

At present, many of the materials data needed for such analyses are not known but have to be assumed. Consequently, the conclusions of current economics studies remain tentative until the required materials data, particularly those related to behavior under irradiation, can be established through tests. 
The ultimate acceptability of fusion reactors as a major national energy source will depend heavily on the safety and environmental impact of their operation. The objective of the Environment and Safety program is to ensure that the development and operation of these reactors occur with minimum adverse effect on the environment and maximum safety for both the public and reactor operating personnel.

As noted earlier, the ultimate fusion reactor is expected to use only deuterium (or materials with slightly higher atomic numbers, such as beryllium and boron) as the fusion fuel to provide power that is essentially free of any radioactive products and has a truly minimal environmental and safety impact. However, first generation fusion reactors will use deuterium and tritium as fuel due to limitations in plasma technology. The environmental drawbacks of deuterium-tritium fusion power are: (1) it produces substantial numbers of neutrons that result in induced radioactivity within the reactor structure, and (2) it requires the handling of the radioisotope tritium.

The present DOE Environmental and Safety Program is a two-pronged effort geared strictly to deuterium-tritium fusion power since it is expected that all near-term fusion power reactors will be of this type. The two major areas are environmental assessment and fusion reactor safety rescarch.

\section{Environmental Assessment}

Formal analysis of environmental impact is required for all major federal actions, including broadly based R\&D programs as well as specitic projects. Environmenlal Assessment makes certain that: (1) environmental considerations are factored into decisions to construst and operate major fusion facilities, and (2) the environmental impact of the fusion power R\&D program is properly evalualed.

A comprehensive analysis of the potential environmental impacts and benefits of fusion energy as a major source of electrical power was completed during FY 1977. The results of the analysis can be summarized as follows:

Potential environmental benefits are:

- Improved nuclear power plant safety. Fusion reactors inherently will have a low probability of accidents.
- Substantial reduction of safeguard concerns. Fusion power plants do not contain any uranium or plutonium which can be diverted for creation of clandestine nuclear weapons.

- Lower routine chemical release. A fusion powerplant does not require the extensive fuel mining, milling, enrichment, fabrication and reprocessing systems required for fission and fossil power plants.

- Elimination of high level waste storage. Fusion reactors neither contain nor create radioactive fission products or transuranic isotopes, such as plutonium.

- Reduced land use.

- Decreased general population radiation dose.

Potential adverse environmental effects are:

- Increased material use. Early fusion reactor designs were large and massive, but current emphasis is on more compact designs.

- Increased employee radiation dose. The complexity of the fusion reactor, as envisioned in early designs, and the requirement for periodic replacement of the reactor inner walls may result in radiation doses to employees.

One unknown is the biological effect of magnetic fields. Magnetic confinement fusion reactors may have magnetic field strengths up to several hundred gauss in areas occupied by plant employees. Although magnetic field strengths can always be reduced by shielding, many years of research lie ahead before it will be known whether these magnetic fields are beneficial, detrimental, or hammless.

Another major activity under Environment Assessment to which public reaction has been favorable is the publication of an Environmental Impact Statement for each major facility before Title I funding began. These statements were prepared and issued for: (1) TFTR at Princeton, New Jersey; (2) Intense Neutron Source (INS) Facility at Los Alamos, New Mexico; and (3) High Flux Neutron Source (HFNS) Facility at Richland, Washington. 


\section{Fusion Reactor Safety Research}

Development of safe, reliable and publicly acceptable fusion power reactors requires identification, evaluation and control of all potential hazards associated with their operation. This must be followed by identifying the engineering safeguards necessary for the safe construction and operation of the reactors.

In a workshop held in September 1977, fusion reactor designers and those studying the safety aspects of fusion discussed and exchanged ideas on major environmental and safety issues. The workshop concluded that all substantive issues have been identified and none are without solutions.

The most obvious potential hazard with early fusion reactors relates to the disposition of inventories of highly permeating tritium and the development of adequate containment and control technology. A major objective of the Tritium Systems Test Assembly (described under "Fusion Systems Engineering") is to demonstrate confinement and control capabilities for systems and tritium inventories which are prototypes of large experimental fusion reactors.
Other Safety Research technology development work is also underway in such areas as:

- Containment and control of liquid lithium.

- Solid radioactive waste handling and disposal.

- Barriers to tritium permeation in fusion reactor systems and components.

Another important aspect of this program is facility accident and safety analysis. Documentation of formal safety analyses is necessary for each fusion reactor facility as a prerequisite to their successful development, ultimate licensing and public acceptance. This necessitates the development of an appropriate methodology for fusion reactor safety analyses (utilizing as a base the techniques developed for evaluating fossil and fission power plants). Such analysis will: (1) assess plant safety in the early design stages, and (2) document incorporation of plant safety features into facility design.

For each major fusion facility, a Preliminary Safety Analysis Report will be prepared prior to construction and a Final Safety Analysis Report will be prepared prior to operation. A draft of the preliminary report for the TFTR has been issued.

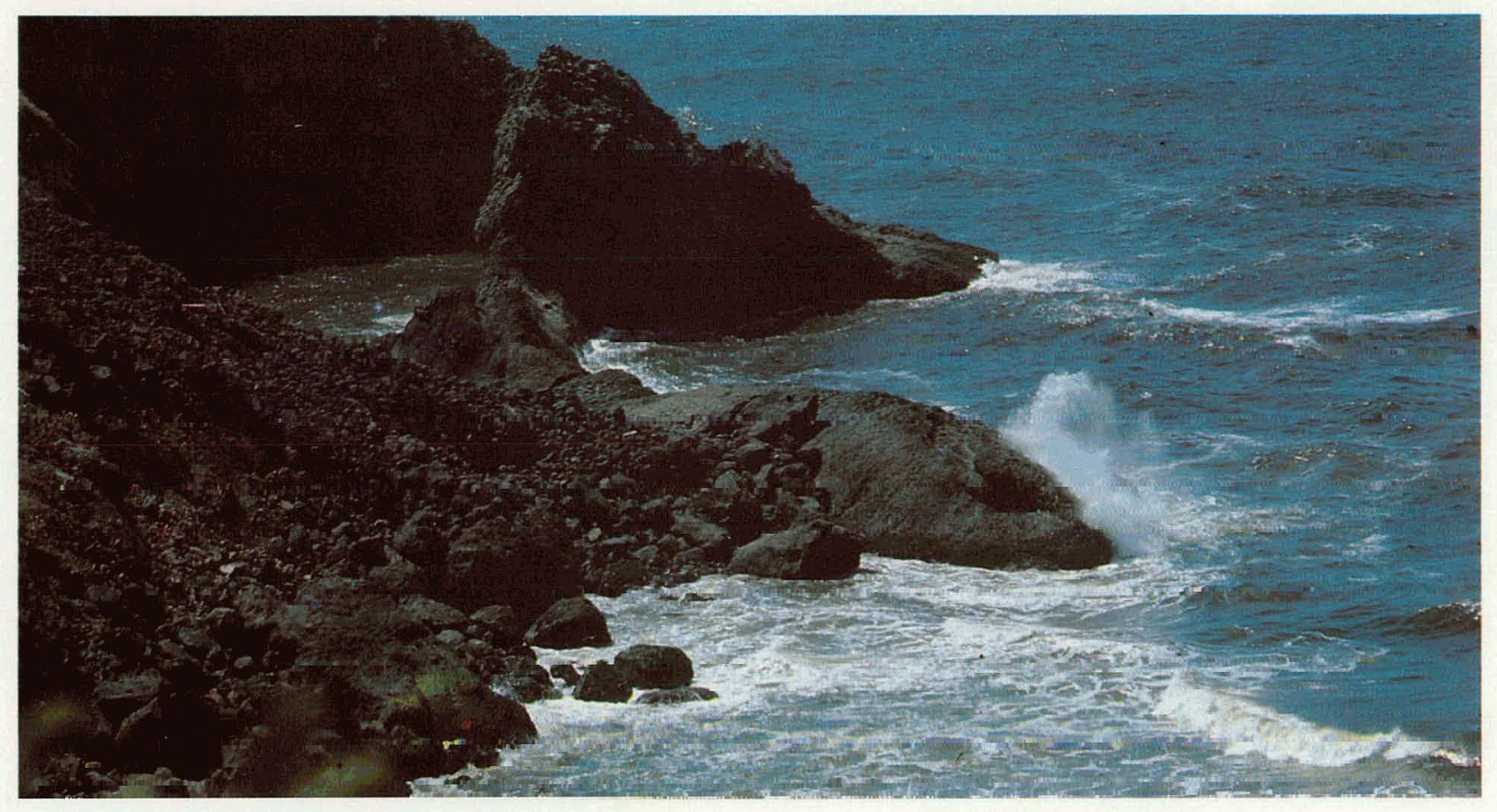

... the oceans contain enough deuterium to supply our needs for a billion years. 


\section{ALTERNATE ENERGY APPLICATIONS}

Although the intended primary commercial application of fusion is to satisfy future demands for large-scale electrical power generation, some alternate applications may be achievable earlier and be directed at other energy markets. Studies conducted to date by the D\&T Program suggest promising possibilities in the following areas:

- Fusion-fisson energy systems

- Generation of industrial process heat

- Production of synthetic chemical fuels

\section{Fusion-Fission Energy Systems (Hybrids)}

Uncertainty surrounds current estimates of U.S. uranium reserves and their mining costs. However, the consensus is that with even modest growth in future nuclear power capacity, the country lacks a sufficient long-term resource of uranium 235 , the only naturally occurring 1 sotope suitable as fuel for fission reactors.

One possible way to stretch the supply and establish nuclear power as a long-term energy resource is to convert thorium, which is abundant, into uranium 233 as a fission reactor fuel. Devices that can perform this conversion are called "hybrids", the fuel producers of fusionfission energy systems. By combining fusion and fission to produce nuclear fuel, net energy could be made available at less stringent fusion performance levels than those required for pure fusion devices alone. As a result, hybrids could possibly contribute to the country's energy production well before pure reactors become commercial realities.

A hybrid reactor is essentially a deuteriumtritium fueled fusion reactor, but differs from its fusion counterpart by the incorporation of fertile materials in its blanket. Fission reactions in the fertile materials, initiated by fusion generated neutrons, release great quantities of energy and simultaneously convert abundant fertile materials to valuable nuclear fuels. If thorium is placed in the blanket, one hybrid reactor could supply supplemental fuel for 10 or more converter fission reactors of comparable thermal rating operating on the thorium/ uranium 233 fuel cycle. Therefore, a comparatively small number of new technology devices, namely fusion machines, could support the operation of a large number of fission reactors.

\section{Generation of Industrial Process Heat}

Over $20 \%$ of the nation's total primary energy is consumed as industrial process heat. To persuade this market to utilize nuclear fission energy would require unjustifiable development commitments by reactor suppliers on the basis of ultimately available natural uranium. However, the problem of limited uranium reserves can be solved by producing nuclear fuel for fission reactors in suitable fusion devices, as

The energetic neutrons of a fusion reactor could be used to produce steam for generating electricity while simultaneously transmuting the fertile material thorium to fissionable uranium 233 for subsequent use in fission-type nuclear powerplants. This combined application device is called a hybrid reactor, and could greatly increase the supply of fission fuel during the transition to pure fusion energy.

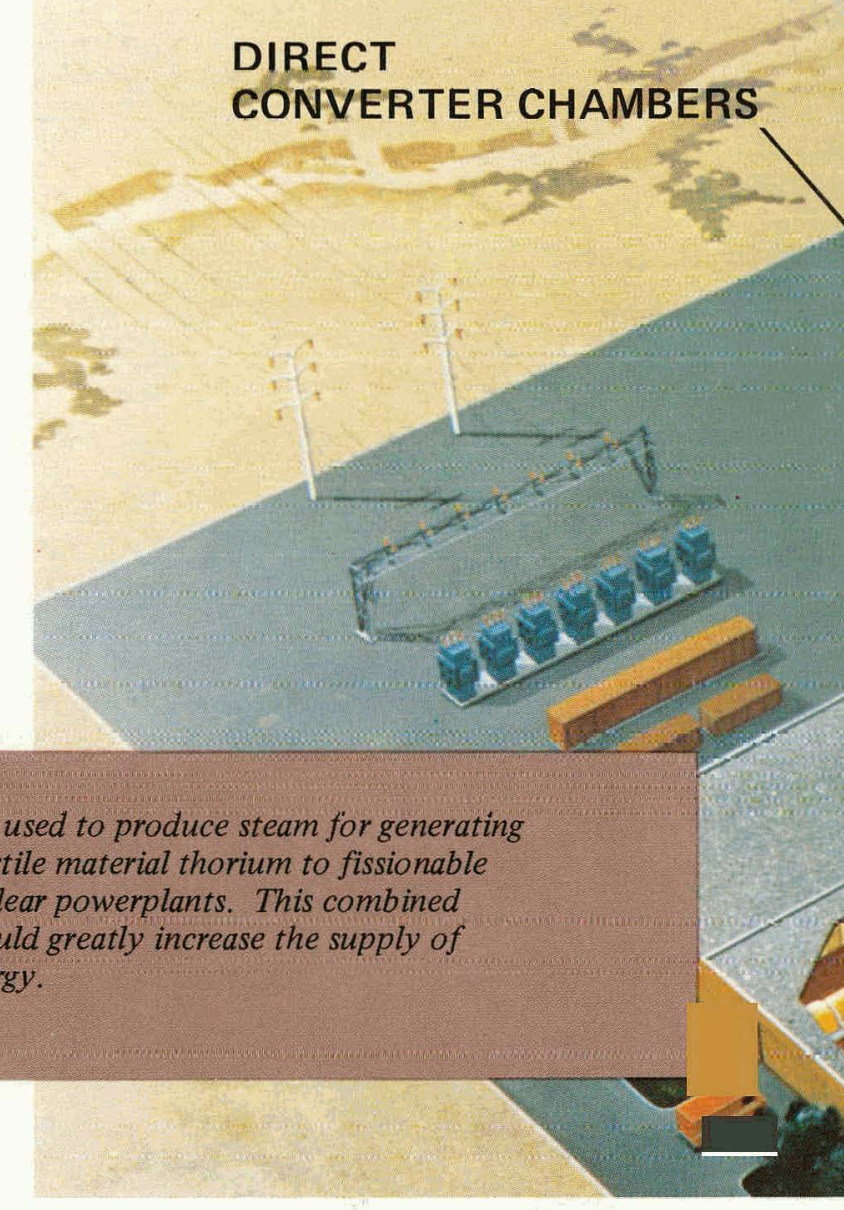


discussed above. In the longer run, pure fusion reactors could provide substantial quantities of industrial process heat because of the expected flexibility for siting near population centers.

\section{Production of Synthetic Chemical Fuels}

Of the nation's total energy consumption, over $70 \%$ is derived from petroleum and natural gas. Although projections of future supply and demand vary widely, the consensus is that pressure on petroleum and gas resources must be relieved.

To conserve petroleum and natural gas would entail, at least, restricting their use to heating, industrial applications and transportation; in fact, those consuming systems for which conversion to electricity could be technically and economically impractical. Using more abundant fuels as substitutes for petroleum and natural gas becomes essential.
Coal is an abundant U.S. resource, and using it to develop hydrocarbon-based synthetic fuels is the most logical and most feasible approach to substitution. However, all established processes are hampered by inefficiency since large quantities of coal must be burned first to supply heat for the process itself. Futhermore, the ensuing release of carbon dioxide in to the atmosphere may produce a potentially serious environmental problem.

Both of these disadvantages can be circumvented by the use of fusion as a clean, unlimited energy supply to produce hydrogen, which then may be employed directly for the production of various forms of synthetic fuel by means of processes well known to the chemical industry. In studies conducted by the Development and Technology Program, several methods of producing hydrogen from water have been identified and are being evaluated.

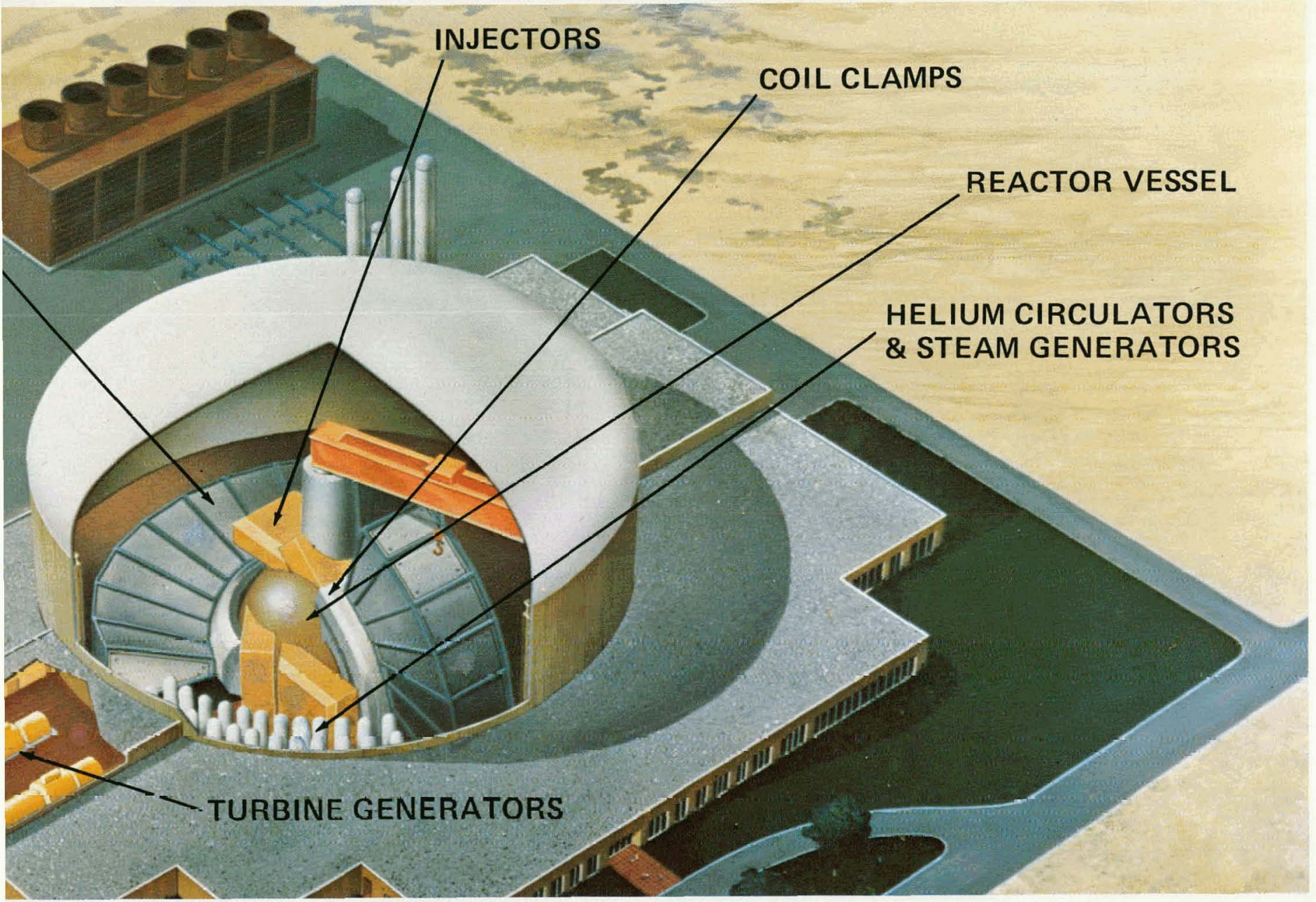




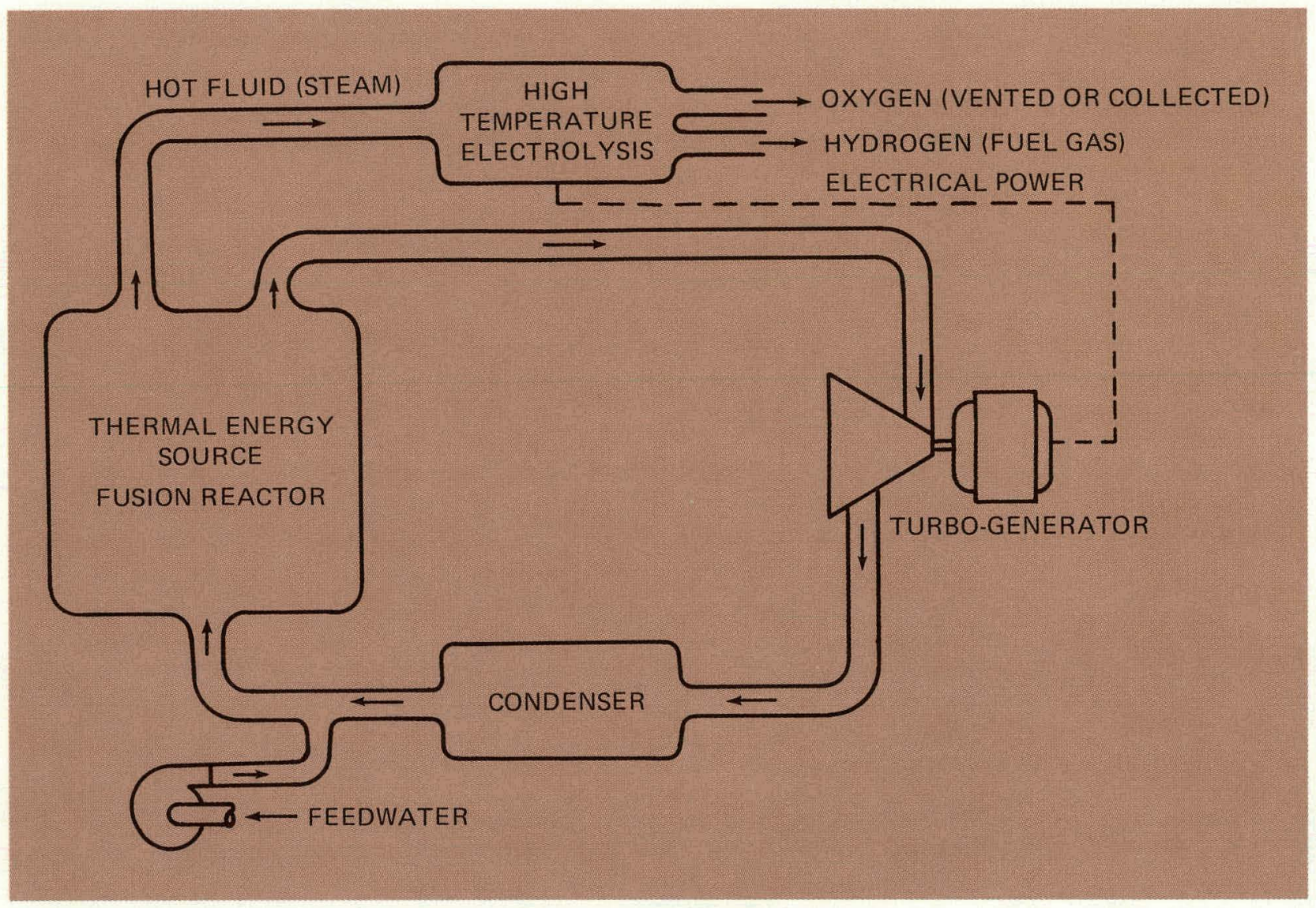

General High-Temperature Electrolysis Process With Conventional Power Cycle

Here is a design for a direct water decomposition system which couples fusion with hightemperature electrolysis. A significant fraction of the energy for direct decomposition of water is provided by thermal energy in the form of steam which is transported from the reactor blanket system and distributed to electrolyzers. Electrical energy, supplied to the electrolytic cells, is generated from a portion of the thermal fusion energy. The diuyram shows a simple process flow in which the three basic elements of the system are coupled, producing hydrogen and oxygen. 


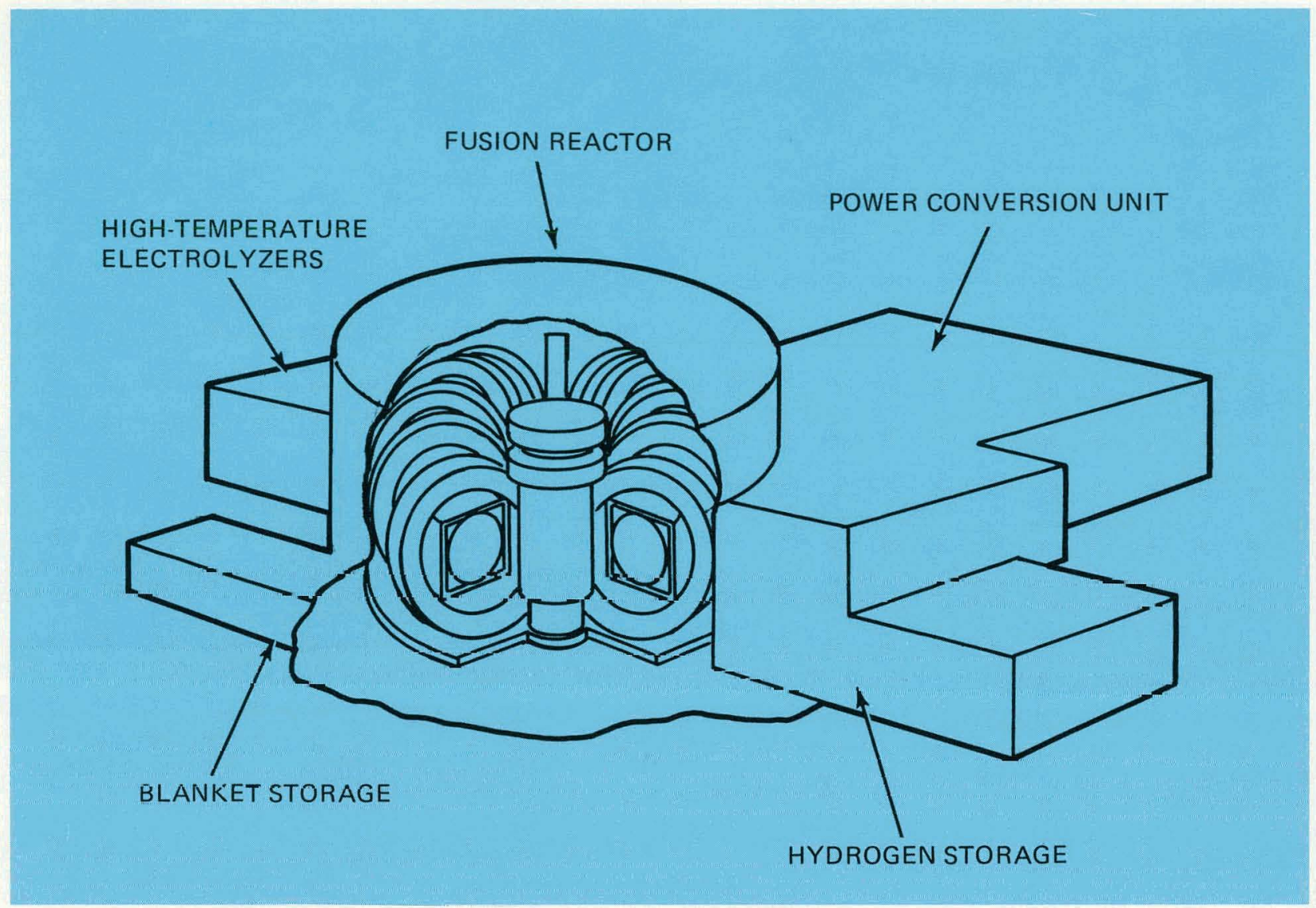

Fusion Reactor High-Temperature Electrolysis System

This is a conceptual design for a direct water decomposition system. The electrolyzers are pressure vessels which surround the fusion reactor and are housed outside the reactor assembly in separate compartments. They are fed steam directly from the high-termperature blankets. The last compartment contains the heat exchangers for hydrogen separation. The hydrogen produced is stored in vessels. The steam/ hydrogen mixture is returned to the blankets to be reheated so as to maintain the hightemperature required for process efficiency. The number of electrolyzers is a function of temperature and hydrogen production requirements. Electricity for the electrolysis process is provided by the power conversion unit, which is based on a helium/steam loop. The electrical generating plant houses the turbines and steam generators as well as auxiliary systems. Tritium facilities are not shown. 
Blanket - The portion of a fusion reactor which absorbs the ultra-fast particles (such as neutrons) and converts their energy to heat. Some blankets will contain special elements which can be transmuted to a more useful material; examples are transmuting lithium to tritium, and thorium to uranium 233.

Deuterium - An isotope of hydrogen naturally occurring in sea water. The deuterium atom consists of a central nucleus, which contains one proton and one neutron, plus an external (or orbital) electron.

Electron - A fundamental particle carrying a single negative electric charge.

EPR - Experimental power reactor - A fusion confinement device that will produce net power, representing a major step toward commercial fusion energy.

Fission - The process whereby heavy atomic nuclei are "split" to release atomic energy. Currently, it is the only nuclear energy process being used to generate commercial electricity.

Fusion - The union (or combination) of two nuclei of the lightest elements to form at least one heavier nucleus. The process is accompanied by the release of large amounts of energy.

Hybrid - A term sometimes used to describe a fusion-fission reactor, in which the neutrons from the fusion device are used to convert fertile material such as thorium to fissionable uranium 233.

Hydrogen - The lightest element; the atoms of hydrogen consist of a nucleus and a single (orbital) electron. Three isotopes of hydrogen are known. Their nuclei contain, respectively, one proton (hydrogen), one proton and one neutron (deuterium), and one proton and two neutrons (tritium).
Ion - An atom (or group of bound atoms) which has acquired an electric charge, for example, by the removal of one or more of the orbital electrons. Since a hydrogen atom, regardless of the isotope, contains a single electron, the loss of this electron leaves a positive ion which is also the nucleus.

Isotopes - Forms of the same element in which the atomic nuclei contain the same number of protons but different numbers of neutrons.

Neutron - A fundamental electrically neutral (or uncharged) particle. All atomic nuclei, with the exception of the lightest isotope of hydrogen, contain one or more neutrons.

Plasma - An ionized gas containing electrically equivalent numbers of positively charged ions and free negatively charged electrons. Somc neutral (atomic) particles may or may not also be present.

Tokamak - A Russian acronym signifying "toroidal magnetic chamber". A doughnut shaped chamber in which the plasma for a fusion reaction will be contained.

TNS - "The Next Step" - an acronym given to the device which will follow the TFTR but come before the EPR.

Tritium - An isotope of hydrogen. The tritium atom consists of a central nucleus, which contains one proton and two neutrons, plus an external (orbital) electron. Tritium differs from the other two isotopes of hydrogen in being radioactive with a half-life of 12.3 years. 


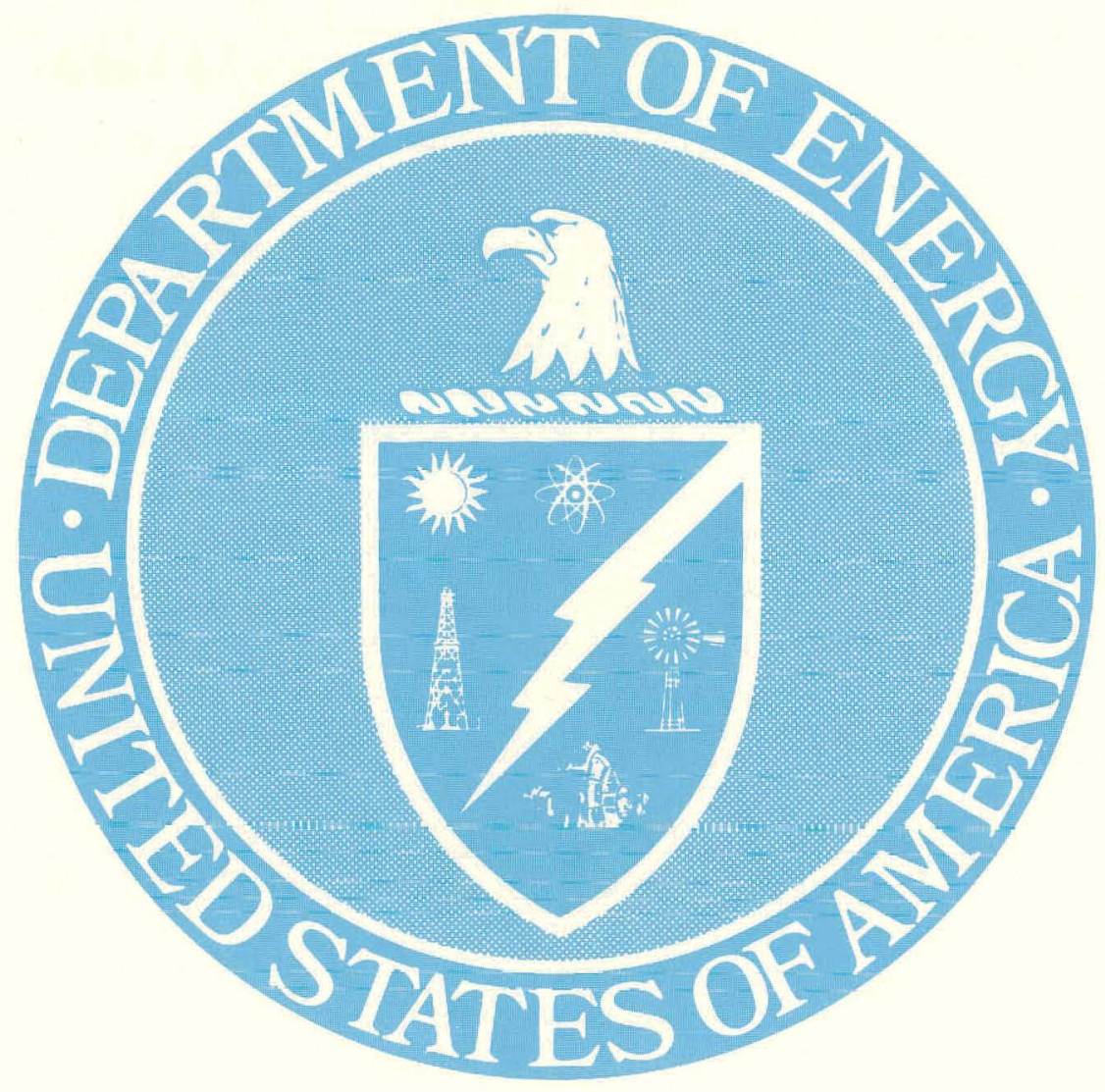



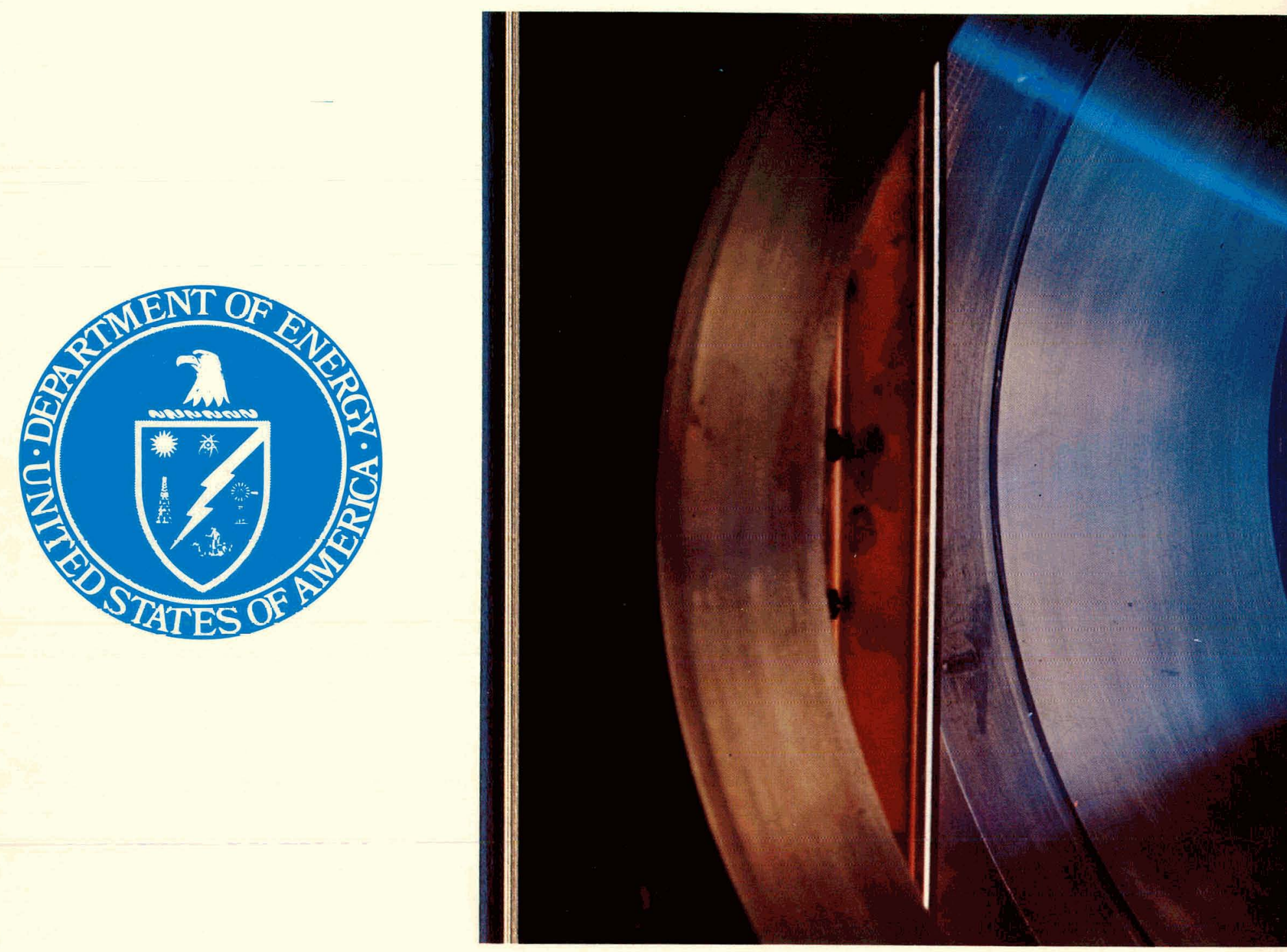